\title{
哬D

\section{The Epidemiology of Alcohol Use Disorders Cross-Nationally: Findings from the World Mental Health Surveys}

\author{
Meyer D. Glantz \\ Chrianna Bharat \\ Louisa Degenhardt \\ Nancy A. Sampson \\ Kate M. Scott
}

See next page for additional authors

Follow this and additional works at: https://digitalcollections.dordt.edu/faculty_work

Part of the Substance Abuse and Addiction Commons

\section{Recommended Citation}

Glantz, M. D., Bharat, C., Degenhardt, L., Sampson, N. A., Scott, K. M., Lim, C. C., Al-Hamzawi, A., Alonso, J., Andrade, L. H., Cardoso, G., De Girolamo, G., Gureje, O., He, Y., Hinkov, H., Karam, E. G., Kovess-Masfety, V., Lasebikan, V., Lee, S., Levinson, D., McGrath, J., Medina-Mora, M., Mihaescu-Pintia, C., Mneimneh, Z., Moskalewicz, J., Navarro-Mateu, F., Posada-Villa, J., Rapsey, C., Stagnaro, J. C., Tachimori, H., Ten Have, M., Tintle, N. L., Torres, Y., Williams, D. R., Ziv, Y., \& Kessler, R. C. (2020). The Epidemiology of Alcohol Use Disorders Cross-Nationally: Findings from the World Mental Health Surveys. Addictive Behaviors, 102 (106128) https://doi.org/10.1016/j.addbeh.2019.106128

This Article is brought to you for free and open access by Dordt Digital Collections. It has been accepted for inclusion in Faculty Work Comprehensive List by an authorized administrator of Dordt Digital Collections. For more information, please contact ingrid.mulder@dordt.edu. 


\title{
The Epidemiology of Alcohol Use Disorders Cross-Nationally: Findings from the World Mental Health Surveys
}

\author{
Abstract \\ Background: Prevalences of Alcohol Use Disorders (AUDs) and Mental Health Disorders (MHDs) in many individual countries have \\ been reported but there are few cross-national studies. The WHO World Mental Health (WMH) Survey Initiative standardizes \\ methodological factors facilitating comparison of the prevalences and associated factors of AUDs in a large number of countries to \\ identify differences and commonalities.
}

Methods: Lifetime and 12-month prevalence estimates of DSM-IV AUDs, MHDs, and associations were assessed in the $29 \mathrm{WMH}$ surveys using the WHO CIDI 3.0.

Results: Prevalence estimates of alcohol use and AUD across countries and WHO regions varied widely. Mean lifetime prevalence of alcohol use in all countries combined was $80 \%$, ranging from $3.8 \%$ to $97.1 \%$. Combined average population lifetime and 12 -month prevalence of AUDs were $8.6 \%$ and $2.2 \%$ respectively and $10.7 \%$ and $4.4 \%$ among non-abstainers. Of individuals with a lifetime AUD, 43.9\% had at least one lifetime MHD and $17.9 \%$ of respondents with a lifetime MHD had a lifetime AUD. For most comorbidity combinations, the MHD preceded the onset of the AUD. AUD prevalence was much higher for men than women. $15 \%$ of all lifetime AUD cases developed before age 18. Higher household income and being older at time of interview, married, and more educated, were associated with a lower risk for lifetime AUD and AUD persistence.

Conclusions: Prevalence of alcohol use and AUD is high overall, with large variation worldwide. The WMH surveys corroborate the wide geographic consistency of a number of well-documented clinical and epidemiological findings and patterns.

\section{Keywords}

alcohol, abuse, dependence, remission, comorbidity, prevalence

\section{Disciplines}

Substance Abuse and Addiction

\section{Authors}

Meyer D. Glantz, Chrianna Bharat, Louisa Degenhardt, Nancy A. Sampson, Kate M. Scott, Carmen C.W. Lim, Ali Al-Hamzawi, Jordi Alonso, Laura Helena Andrade, Graca Cardoso, Giovanni De Girolamo, Oye Gureje, Yanling He, Hristo Hinkov, Elie G. Karam, Viviane Kovess-Masfety, Victor Lasebikan, Sing Lee, Daphna Levinson, John McGrath, Maria-Elena Medina-Mora, Constanta Mihaescu-Pintia, Zeina Mneimneh, Jacek Moskalewicz, Fernando Navarro-Mateu, Jose Posada-Villa, Charlene Rapsey, Juan Carlos Stagnaro, Hisateru Tachimori, Margreet Ten Have, Nathan L. Tintle, Yolanda Torres, David R. Williams, Yuval Ziv, and Ronald C. Kessler 


\section{The epidemiology of alcohol use disorders cross-nationally: Findings from the World Mental Health Surveys}

Meyer D. Glantz ${ }^{\mathrm{a}, *}$, Chrianna Bharat ${ }^{\mathrm{b}}$, Louisa Degenhardt ${ }^{\mathrm{b}}$, Nancy A. Sampson ${ }^{\mathrm{c}}$, Kate M. Scott ${ }^{\mathrm{d}}$, Carmen C.W. Lim ${ }^{\mathrm{e}}$, Ali Al-Hamzawi ${ }^{\mathrm{f}}$, Jordi Alonso, ${ }^{\text {,ai, aj }}$, Laura Helena Andrade ${ }^{\mathrm{h}}$, Graca Cardoso ${ }^{\mathrm{i}}$, Giovanni De Girolamo ${ }^{\mathrm{j}}$, Oye Gureje ${ }^{\mathrm{k}}$, Yanling He ${ }^{1}$, Hristo Hinkov ${ }^{\mathrm{m}}$, Elie G. Karam ${ }^{\mathrm{n}, \mathrm{ak}, \mathrm{al}}$, Georges Karam $^{\mathrm{o}, \mathrm{al}}$, Viviane Kovess-Masfety ${ }^{\mathrm{p}}$, Victor Lasebikan ${ }^{\mathrm{q}}$, Sing Lee ${ }^{\mathrm{r}}$, Daphna Levinson ${ }^{\mathrm{s}}$, John McGrath $^{\mathrm{t}, \mathrm{am} \text {, an }}$, Maria-Elena Medina-Mora ${ }^{\mathrm{u}}$, Constanta Mihaescu-Pintia ${ }^{\mathrm{v}}$, Zeina Mneimneh ${ }^{\mathrm{w}}$, Jacek Moskalewicz ${ }^{\mathrm{x}}$, Fernando Navarro-Mateu ${ }^{\mathrm{y}}$, José Posada-Villa ${ }^{\mathrm{z}}$, Charlene Rapsey ${ }^{\mathrm{aa}}$, Juan Carlos Stagnaro $^{\mathrm{ab}}$, Hisateru Tachimori ${ }^{\mathrm{ac}}$, Margreet Ten Have ${ }^{\mathrm{ad}}$, Nathan Tintle ${ }^{\mathrm{ae}}$, Yolanda Torres ${ }^{\mathrm{af}}$, David R. Williams ${ }^{\mathrm{ag}}$, Yuval Ziv ${ }^{\text {ah }}$, Ronald C. Kessler ${ }^{\mathrm{c}}$, on behalf of the WHO World Mental Health Survey Collaborators

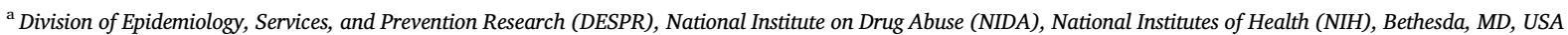

${ }^{\mathrm{b}}$ National Drug and Alcohol Research Centre (NDARC), UNSW, Sydney, Australia

${ }^{\mathrm{c}}$ Department of Health Care Policy, Harvard Medical School, Boston, MA, USA

${ }^{\mathrm{d}}$ Department of Psychological Medicine, University of Otago, Dunedin, Otago, New Zealand

e Queensland Centre for Mental Health Research and Queensland Brain Institute, The University of Queensland, St. Lucia, Queensland, Australia

${ }^{\mathrm{f}}$ College of Medicine, Al-Qadisiya University, Diwaniya governorate, Iraq

${ }^{\mathrm{g}}$ Health Services Research Unit, IMIM-Hospital del Mar Medical Research Institute, Barcelona, Spain

${ }^{\mathrm{h}}$ Núcleo de Epidemiologia Psiquiátrica - LIM 23, Instituto de Psiquiatria Hospital das Clinicas da Faculdade de Medicina da Universidade de São Paulo, Brazil

${ }^{\mathrm{i}}$ Lisbon Institute of Global Mental Health and Chronic Diseases Research Center (CEDOC), NOVA Medical School, Faculdade de Ciências Médicas, Universidade Nova de Lisboa, Lisbon, Portugal

${ }^{\mathrm{j}}$ Unit of Epidemiological and Evaluation Psychiatry, Istituti di Ricovero e Cura a Carattere Scientifico (IRCCS)-St. John of God Clinical Research Centre, Brescia, Italy

${ }^{\mathrm{k}}$ FRCPsych, Department of Psychiatry, University College Hospital, Ibadan, Nigeria

${ }^{1}$ Shanghai Mental Health Center, Shanghai Jiao Tong University, School of Medicine, Shanghai, China

${ }^{\mathrm{m}}$ National Center of Public Health and Analyses, Sofia, Bulgaria

${ }^{\mathrm{n}}$ Department of Psychiatry and Clinical Psychology, Faculty of Medicine, Balamand University, Beirut, Lebanon

${ }^{\circ}$ Department of Psychiatry and Clinical Psychology, St George Hospital University Medical Center, Balamand University, Faculty of Medicine, Beirut, Lebanon

${ }^{\mathrm{p}}$ Ecole des Hautes Etudes en Santé Publique (EHESP), EA 4057, Paris Descartes University, Paris, France

${ }^{\mathrm{q}}$ Department of Psychiatry, College of Medicine, University of Ibadan, Ibadan, Nigeria

${ }^{\mathrm{r}}$ Department of Psychiatry, Chinese University of Hong Kong, Tai Po, Hong Kong

${ }^{s}$ Mental Health Services, Ministry of Health, Jerusalem, Israel

${ }^{t}$ Queensland Centre for Mental Health Research, The Park Centre for Mental Health, Wacol, Queensland, Australia

${ }^{\mathrm{u}}$ National Institute of Psychiatry Ramón de la Fuente Muñiz, Mexico City, Mexico

${ }^{\mathrm{v}}$ National School of Public Health, Management and Professional Development, Bucharest, Romania

${ }^{\mathrm{w}}$ Survey Research Center, Institute for Social Research, University of Michigan, Ann Arbor, MI, USA

${ }^{\mathrm{x}}$ Institute of Psychiatry and Neurology, Warsaw, Poland

${ }^{y}$ UDIF-SM, Subdirección General de Planificación, Innovación y Cronicidad, Servicio Murciano de Salud, IMIB-Arrixaca, CIBERESP-Murcia, Murcia, Spain

${ }^{\mathrm{z}}$ Colegio Mayor de Cundinamarca University, Faculty of Social Sciences, Bogota, Colombia

${ }^{\text {aa }}$ PGDipClinPsych, University of Otago, Dunedin School of Medicine, Department of Psychological Medicine, New Zealand

${ }^{\mathrm{ab}}$ Departamento de Psiquiatría y Salud Mental, Facultad de Medicina, Universidad de Buenos Aires, Argentina

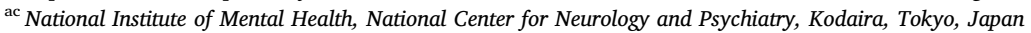

${ }^{\text {ad }}$ Trimbos-Instituut, Netherlands Institute of Mental Health and Addiction, Utrecht, the Netherlands

ae Department of Mathematics, Statistics and Computer Science, Dordt College, Sioux Center, Iowa, USA

${ }^{\text {af }}$ Center for Excellence on Research in Mental Health, CES University, Medellin, Colombia

${ }^{\mathrm{ag}}$ Department of Social and Behavioral Sciences, Harvard T.H. Chan School of Public Health, Boston, MA, USA

${ }^{\text {ah }}$ Mental Health Services, Israeli Ministry of Health, 39 Yermiyahu St, Jerusalem 9101002, Israel

${ }^{\text {ai }}$ CIBER en Epidemiología y Salud Pública (CIBERESP), Spain

${ }^{\text {aj }}$ Pompeu Fabra University (UPF), Barcelona, Spain

${ }^{\text {ak }}$ Department of Psychiatry and Clinical Psychology, St George Hospital University Medical Center, Beirut, Lebanon

${ }^{\text {al }}$ Institute for Development Research Advocacy and Applied Care (IDRAAC), Beirut, Lebanon

\footnotetext{
* Corresponding author.

E-mail address: mglantz@nida.nih.gov (M.D. Glantz).
} 
${ }^{a m}$ Queensland Brain Institute, University of Queensland, St. Lucia, Queensland, Australia

${ }^{\text {an }}$ National Centre for Register-Based Research, Aarhus University, Aarhus, Denmark

H I G H L I G H T S

- Alcohol use and alcohol use disorder (AUD) prevalence rates varied across countries.

- Mean lifetime prevalences were $80 \%$ for alcohol use and $8.6 \%$ for AUD.

- Risk of AUD onset began in adolescence, with 15\% of all cases developed by age 18 .

- Comorbidity was high, with other mental disorders most often preceding AUD onset.

- Patterns of AUDs and correlates were consistent across counties.

\section{A R T I C L E I N F O}

\section{Keywords:}

Alcohol

Abuse

Dependence

Remission

Comorbidity

Prevalence

\begin{abstract}
A B S T R A C T
Background: Prevalences of Alcohol Use Disorders (AUDs) and Mental Health Disorders (MHDs) in many individual countries have been reported but there are few cross-national studies. The WHO World Mental Health (WMH) Survey Initiative standardizes methodological factors facilitating comparison of the prevalences and associated factors of AUDs in a large number of countries to identify differences and commonalities.

Methods: Lifetime and 12-month prevalence estimates of DSM-IV AUDs, MHDs, and associations were assessed in the $29 \mathrm{WMH}$ surveys using the WHO CIDI 3.0.

Results: Prevalence estimates of alcohol use and AUD across countries and WHO regions varied widely. Mean lifetime prevalence of alcohol use in all countries combined was $80 \%$, ranging from $3.8 \%$ to $97.1 \%$. Combined average population lifetime and 12-month prevalence of AUDs were $8.6 \%$ and $2.2 \%$ respectively and $10.7 \%$ and 4.4\% among non-abstainers. Of individuals with a lifetime AUD, 43.9\% had at least one lifetime MHD and 17.9\% of respondents with a lifetime MHD had a lifetime AUD. For most comorbidity combinations, the MHD preceded the onset of the AUD. AUD prevalence was much higher for men than women. $15 \%$ of all lifetime AUD cases developed before age 18. Higher household income and being older at time of interview, married, and more educated, were associated with a lower risk for lifetime AUD and AUD persistence.

Conclusions: Prevalence of alcohol use and AUD is high overall, with large variation worldwide. The WMH surveys corroborate the wide geographic consistency of a number of well-documented clinical and epidemiological findings and patterns.
\end{abstract}

\section{Introduction}

Alcohol Use Disorders (AUDs) are serious psychiatric conditions often leading to major adverse consequences. The 2018 World Health Organization's (WHO) Global Status Report on Alcohol and Health determined that in 2016 harmful use of alcohol caused approximately 3 million deaths (or $5.3 \%$ of all deaths), more than hypertension and diabetes combined. The WHO report estimated that $5.1 \%$ of the global burden of disease and injury, equivalent to 132.6 million Disabilityadjusted Life Years (DALYs), was caused by alcohol use(World Health Organization, 2018). In 2016, an estimated 2.3 billion people were current drinkers and 283 million people aged $15+$ years had an AUD (5.1\% of adults). The economic burden of alcohol use has been estimated to be more than $1 \%$ of the gross national product in middle and high income countries(Rehm, Mathers, Popova, et al., 2009). Alcohol use was the 7th leading risk for early death and disability(GBD 2016 Alcohol Collaborators, 2018). Despite some decrease in per capita alcohol use in some WHO regions, worldwide per capita alcohol consumption is predicted to increase over the next 10 years with a possible increase in disease burden(World Health Organization, 2018). Multicountry epidemiologic data on AUDs can enable better understanding of patterns and characteristics of AUDs providing necessary information for prevention and treatment implementation and policy. There is little cross-national standardized data available(Baxter, Patton, Scott, et al., 2013; Steel, Marnane, Iranpour, et al., 2014). It is difficult to compare findings from different studies as they generally have not used equivalent assessments, administrations, diagnostic systems, sampling and analysis approaches. A few limited multi-country or regional studies using a standardized assessment have been conducted. One early notable effort used the Diagnostic Interview Schedule(Robins, Helzer, Croughan, et al., 1981) which includes an assessment of DSM-III (American Psychiatric Association, 1980) alcohol abuse and dependence to assess samples in coordinated studies in 10 different cultural regions(Helzer \& Canino, 1992). There was wide variation in the lifetime prevalence rates of DSM-III alcohol abuse and/or dependence ranging from $0.45 \%$ in Shanghai to $22 \%$ in Korea and $23 \%$ in United States native Mexican Americans although there was similarity in a number of associated variables.

The WHO World Mental Health (WMH) Survey Initiative(Kessler \& Üstün, 2004) standardizes survey design and implementation procedures that facilitate the comparison of estimates of prevalence and correlates of AUDs in a large number of participating countries(Kessler, Abelson, Demler, et al., 2004; Kessler, Heeringa, Pennell, et al., 2018; Kessler \& Üstün, 2004), making the study especially useful for investigating cross-national characteristics of disorders(Glantz, MedinaMora, Petukhova, et al., 2014). This paper reports findings on the prevalences and correlates of AUDs in the WMH countries.

\section{Methods}

Data for this paper come from 29 WMH surveys carried out in 27 countries or country regions between 2001 and 2015. The list of participating countries, their World Bank income classification(World Bank, 2012), and the sample characteristics for each country including the sample sizes are shown in Table 1.

Mental and substance use disorders were assessed using the WHO Composite International Diagnostic Interview (CIDI) Version 3.0, a validated fully-structured lay-administered interview(Haro, ArbabzadehBouchez, Brugha, et al., 2006) generating lifetime and 12-month prevalence estimates of DSM-IV-TR(American Psychiatric Association, 2000) mood, anxiety, behavioral, and substance use disorders(Kessler \& Üstün, 2004). The CIDI assesses AUDs by asking a series of questions that operationalize the DSM-IV symptom criteria for Alcohol Abuse (ALA) and Alcohol Dependence (ALD). Respondents who met criteria for either ALA or ALD were 
Table 1

WMH sample characteristics by World Bank income categories.

\begin{tabular}{|c|c|c|c|c|c|c|}
\hline \multirow[t]{2}{*}{ Country } & \multirow[t]{2}{*}{ Sampling } & \multirow[t]{2}{*}{ Field dates } & \multirow[t]{2}{*}{ Age range ${ }^{\mathrm{b}}$} & \multicolumn{2}{|c|}{ Sample size } & \multirow[t]{2}{*}{ Response rate } \\
\hline & & & & Part 1 & Part 2 & \\
\hline \multicolumn{7}{|c|}{ Low and lower-middle income countries } \\
\hline Colombia & All urban areas of the country (about $73 \%$ of the total national population) & 2003 & $18-65$ & 4426 & 2381 & $87.7 \%$ \\
\hline Iraq & Nationally representative & $2006-7$ & $18-96$ & 4332 & 4332 & $95.2 \%$ \\
\hline Nigeria & 21 of the 36 states in the country (about $57 \%$ of the national population) & $2002-4$ & $18-100$ & 6752 & 2143 & $79.3 \%$ \\
\hline China & Beijing and Shanghai metropolitan areas & $2001-3$ & $18-70$ & 5201 & 1628 & $74.7 \%$ \\
\hline Peru & All urban areas of the country & $2004-5$ & $18-65$ & 3930 & 1801 & $90.2 \%$ \\
\hline Ukraine & Nationally representative & 2002 & $18-91$ & 4725 & 1720 & $78.3 \%$ \\
\hline Total & & & & 29,366 & 14,005 & $82.8 \%$ \\
\hline \multicolumn{7}{|c|}{ Upper-middle income countries } \\
\hline Brazil & São Paulo metropolitan area & $2005-8$ & $18-93$ & 5037 & 2942 & $81.3 \%$ \\
\hline Bulgaria & Nationally representative & $2002-6$ & $18-98$ & 5318 & 2233 & $72.0 \%$ \\
\hline Colombia & Medellin metropolitan area & 2011-12 & $19-65$ & 3261 & 1673 & $97.2 \%$ \\
\hline Lebanon & Nationally representative & $2002-3$ & $18-94$ & 2857 & 1031 & $70.0 \%$ \\
\hline Mexico & All urban areas of the country (about $75 \%$ of the total national population) & $2001-2$ & $18-65$ & 5782 & 2362 & $76.6 \%$ \\
\hline Romania & Nationally representative & $2005-6$ & $18-96$ & 2357 & 2357 & $70.9 \%$ \\
\hline South Africa & Nationally representative & $2002-4$ & $18-92$ & 4315 & 4315 & $87.1 \%$ \\
\hline \multicolumn{7}{|c|}{ High income countries } \\
\hline Argentina & Nationally representative & 2015 & $18-98$ & 3927 & 2116 & $77.3 \%$ \\
\hline Australia & Nationally representative & 2007 & $18-85$ & 8463 & 8463 & $60.0 \%$ \\
\hline Belgium & Nationally representative & $2001-2$ & $18-95$ & 2419 & 1043 & $50.6 \%$ \\
\hline France & Nationally representative & $2001-2$ & $18-97$ & 2894 & 1436 & $45.9 \%$ \\
\hline Germany & Nationally representative & $2002-3$ & $19-95$ & 3555 & 1323 & $57.8 \%$ \\
\hline Israel & Nationally representative & $2003-4$ & $21-98$ & 4859 & 4859 & $72.6 \%$ \\
\hline Italy & Nationally representative & $2001-2$ & $18-100$ & 4712 & 1779 & $71.3 \%$ \\
\hline Japan & Eleven metropolitan areas & $2002-6$ & $20-98$ & 4129 & 1682 & $55.1 \%$ \\
\hline The Netherlands & Nationally representative & $2002-3$ & $18-95$ & 2372 & 1094 & $56.4 \%$ \\
\hline New Zealand & Nationally representative & 2004-5 & $18-98$ & 12,790 & 7312 & $73.3 \%$ \\
\hline North Ireland & Nationally representative & $2005-8$ & $18-97$ & 4340 & 1986 & $68.4 \%$ \\
\hline Poland & Nationally representative & $2010-11$ & $18-65$ & 10,081 & 4000 & $50.4 \%$ \\
\hline Portugal & Nationally representative & $2008-9$ & $18-81$ & 3849 & 2060 & $57.3 \%$ \\
\hline Spain & Nationally representative & $2001-2$ & $18-98$ & 5473 & 2121 & $78.6 \%$ \\
\hline Spain & Murcia region & 2010-12 & $18-96$ & 2621 & 1459 & $67.4 \%$ \\
\hline United States & Nationally representative & $2001-3$ & $18-99$ & 9282 & 5692 & $70.9 \%$ \\
\hline Total & & & & 85,766 & 48,425 & $63.1 \%$ \\
\hline Overall sample & & & & 144,059 & 79,343 & $69.2 \%$ \\
\hline
\end{tabular}

a The World Bank (2018) Data. Accessed August 2018 at: http://data.worldbank.org/country. Some of the WMH countries have moved into new income cate-

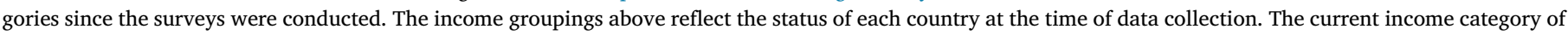
each country is available at the preceding URL.

$\mathrm{b}$ For the purposes of cross-national comparisons we limit the sample to those $18+$.

c The response rate is calculated as the ratio of the number of households in which an interview was completed to the number of households originally sampled,

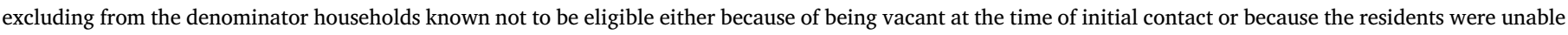
to speak the designated languages of the survey.

considered to have an AUD. Consistent with DSM-IV, any respondents who met criteria for both AUD disorders were diagnosed with ALD.

In an effort to reduce respondent burden a two-part sampling design was used in which all respondents were administered a Part I interview that contained questions about disorders of primary interest to the WMH investigators. A Part II sample, consisting of $100 \%$ of the Part I respondents who met lifetime criteria for any of the disorders assessed in Part I plus a probability sample (typically in the range between $20 \%$ and $33 \%$ depending on the country) of other Part I respondents were administered Part II of the survey. The Part II sample included questions about disorders of secondary interest along with questions about risk factors and consequences of disorders. The non-certainty respondents in the Part II sample were weighted by the inverse of their probability of selection so that weighted prevalence estimates of Part I disorders in the Part II sample are identical to unweighted estimates of these disorders in the Part I sample. Weights were also used to match the samples to population socio-demographic distributions. As discussed in detail elsewhere,(Heeringa, Wells, Hubbard, et al., 2008) the sequence of steps in calculating analysis weights was the same across WMH surveys but differed in exact procedures depending on the sample frame and access to population data for post-survey adjustments. A total of 123,237 respondents across the 29 surveys were assessed for AUDs. The
Part II sample includes 79,343 respondents. Further details on the WMH surveys are summarized in the Appendix Methods.

\section{Data analysis}

All analyses were based on weighted data, accounting for stratification and clustering. Standard errors were estimated using Taylor series linearization as implemented in Statistical Analysis System ${ }^{\circledR}$ (SAS) Version 9.4(SAS Institute Inc, 2019). SAS PROC LIFETEST was used to produce life-table estimates of the age-of-onset (AOO) distributions of AUD and are reported as weighted prevalences. The associations of sociodemographic variables (see Appendix Methods for full list) with lifetime AUD prevalence as of given ages were assessed using discrete-time logistic regression analyses with person-year the unit of analysis. Similar analyses using standard logistic regression were used to investigate correlates of past year AUD among non-abstainers defined as those who report at least some use of alcohol in their lifetimes. Results are presented as odds ratios (OR) and 95\% confidence intervals (CI). Tests of significance were evaluated using Wald $F$ tests based on design-corrected coefficient variance-covariance matrices with statistical significance defined at the 2-tailed 0.05 level. 


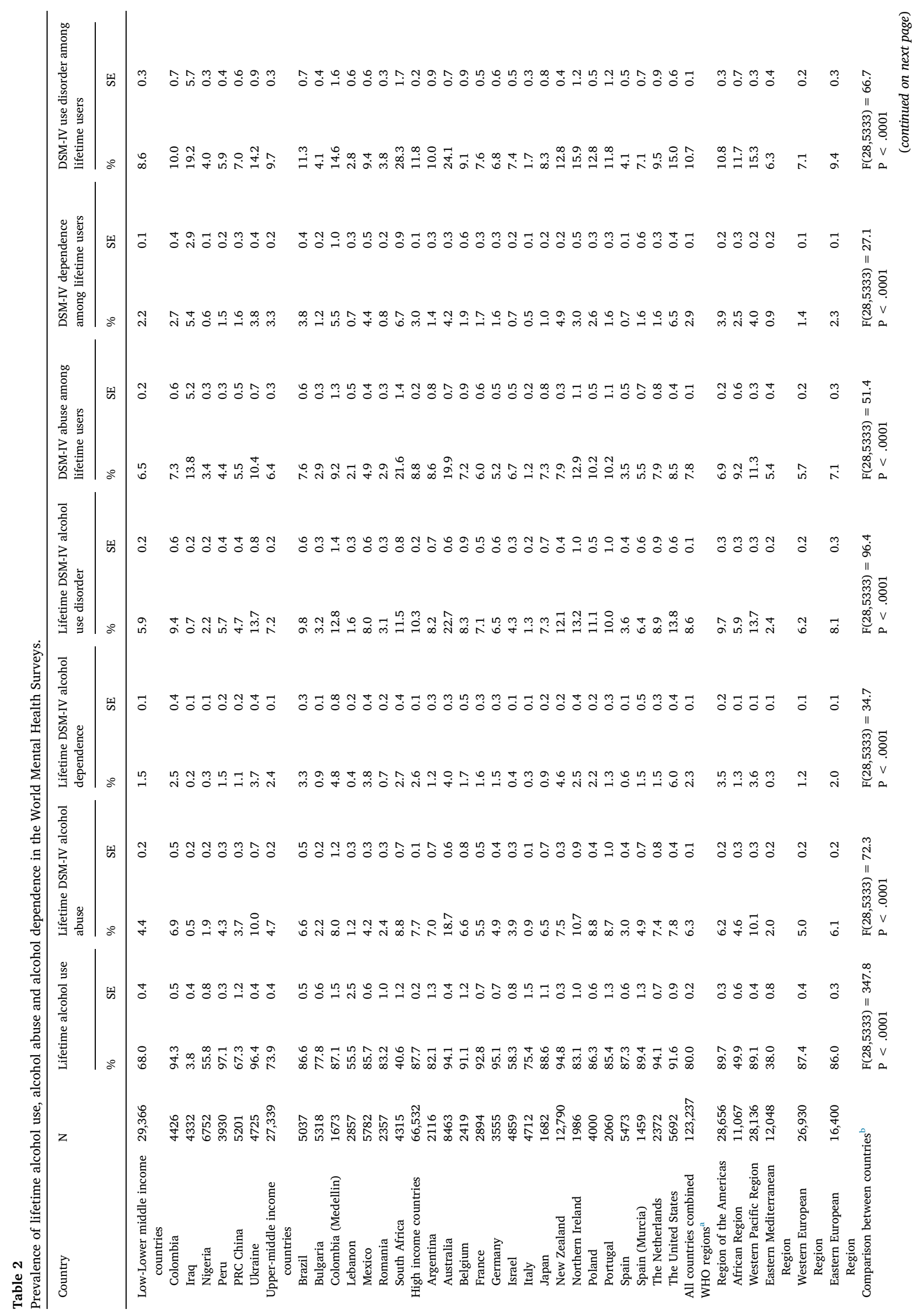




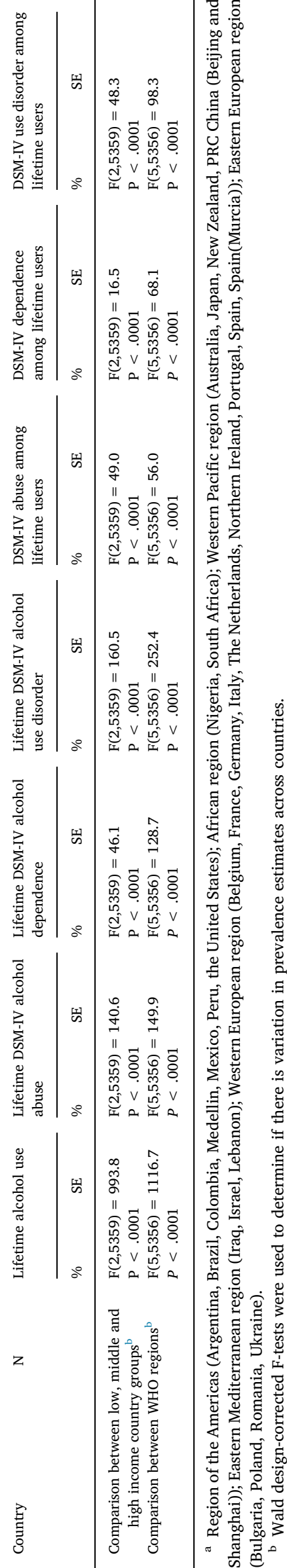

\section{Results}

\subsection{Lifetime prevalence}

Table 2 shows the lifetime prevalence of alcohol use, ALA, ALD and AUDs for each of the surveys, the countries combined, the countries grouped by World Bank income levels, and the WHO regions. There are significant differences in base rate prevalences of lifetime alcohol use and all DSM-IV diagnoses across countries, income levels and regions, as well as significant differences in prevalences when considered only among non-abstainers.

The mean lifetime prevalence of alcohol use in all countries combined was $80 \%$, ranging from $3.8 \%$ in Iraq to $97.1 \%$ in Peru. The average lifetime prevalence of ALA for all countries was $6.3 \%$, ranging from $0.5 \%$ in Iraq to $18.7 \%$ in Australia. The average lifetime prevalence of ALD for all countries was $2.3 \%$, ranging from $0.2 \%$ in Iraq to $6.0 \%$ in the United States. As expected, the lifetime prevalence of ALD was lower than ALA cross-nationally and for all within-country comparisons. The lifetime prevalence of AUDs for all countries combined was $8.6 \%$ and ranged from $0.7 \%$ in Iraq to $22.7 \%$ in Australia.

The lifetime prevalence of AUDs among non-abstainers for all countries combined was $10.7 \%$. Once conditioned upon lifetime alcohol use, there was a noticeable shift in the ordering of prevalence across surveys. When excluding lifetime alcohol abstainers, the highest prevalence of lifetime AUD was found in South Africa (28.3\%) exceeding that of Australia (24.1\%) which had the highest unconditioned AUD prevalence. The lowest conditional prevalences were found for Italy with estimates of $1.2 \%$ for ALA, $0.5 \%$ for ALD, and $1.7 \%$ for AUD. When all survey participants were considered, Iraq had the lowest prevalence of AUDs. However, once conditioning on lifetime use, Iraq fell in the top three of all surveys for AUD prevalence indicating a low level of overall use but a high risk of AUD among users.

Unconditional lifetime prevalence of AUDs shows a clear positive trend with country income level, increasing from 5.9\% for AUDs in low/lower-middle income countries to $7.2 \%$ in upper-middle income countries and $10.3 \%$ in high-income countries. Comparisons of AUD diagnoses by income group remain significant when conditioning upon lifetime use of alcohol but the trend was less consistent. Comparing between WHO regions, prevalence rates of AUDs were lowest among the Eastern Mediterranean surveys and highest among the Western Pacific surveys, regardless of whether conditioning on alcohol use or not.

\subsection{Past-year prevalence}

Table 3 shows the prevalences of past-year alcohol use, ALA, ALD and AUDs for all countries, income levels and WHO regions, as well as past-year diagnoses conditional on past-year use. There were significant differences in unconditional and conditional past-year alcohol use and diagnoses across countries. The average 12-month prevalence of alcohol use was $52.3 \%$, ranging from $1.7 \%$ in Iraq to $76.9 \%$ in Australia. The average 12-month prevalence of ALA for all countries was $1.3 \%$ and ranges from $0.1 \%$ in Iraq and Japan to $3.7 \%$ in the Ukraine. Similar to observations among lifetime prevalences, within-survey comparisons show past-year rates of ALA most often exceed past-year ALD. The average past-year prevalence of AUDs for all countries combined was $2.2 \%$ and ranges from $0.1 \%$ in Iraq to $5.9 \%$ in the Ukraine.

Conditioning on past year alcohol use, the average past year prevalence for all countries combined was $2.6 \%$ for ALA, $1.8 \%$ for ALD, and $4.4 \%$ for AUD. Iraq had the highest past year prevalence rate (joint with New Zealand) of any survey for AUDs among past-year users (7.3\%) which sharply contrasts with its unconditional past-year AUD estimate in which it reported the lowest of any survey $(0.1 \%)$. The lowest conditional past year prevalence of AUDs was from Japan (1.1\%).

There were significant differences in past-year prevalence estimates 


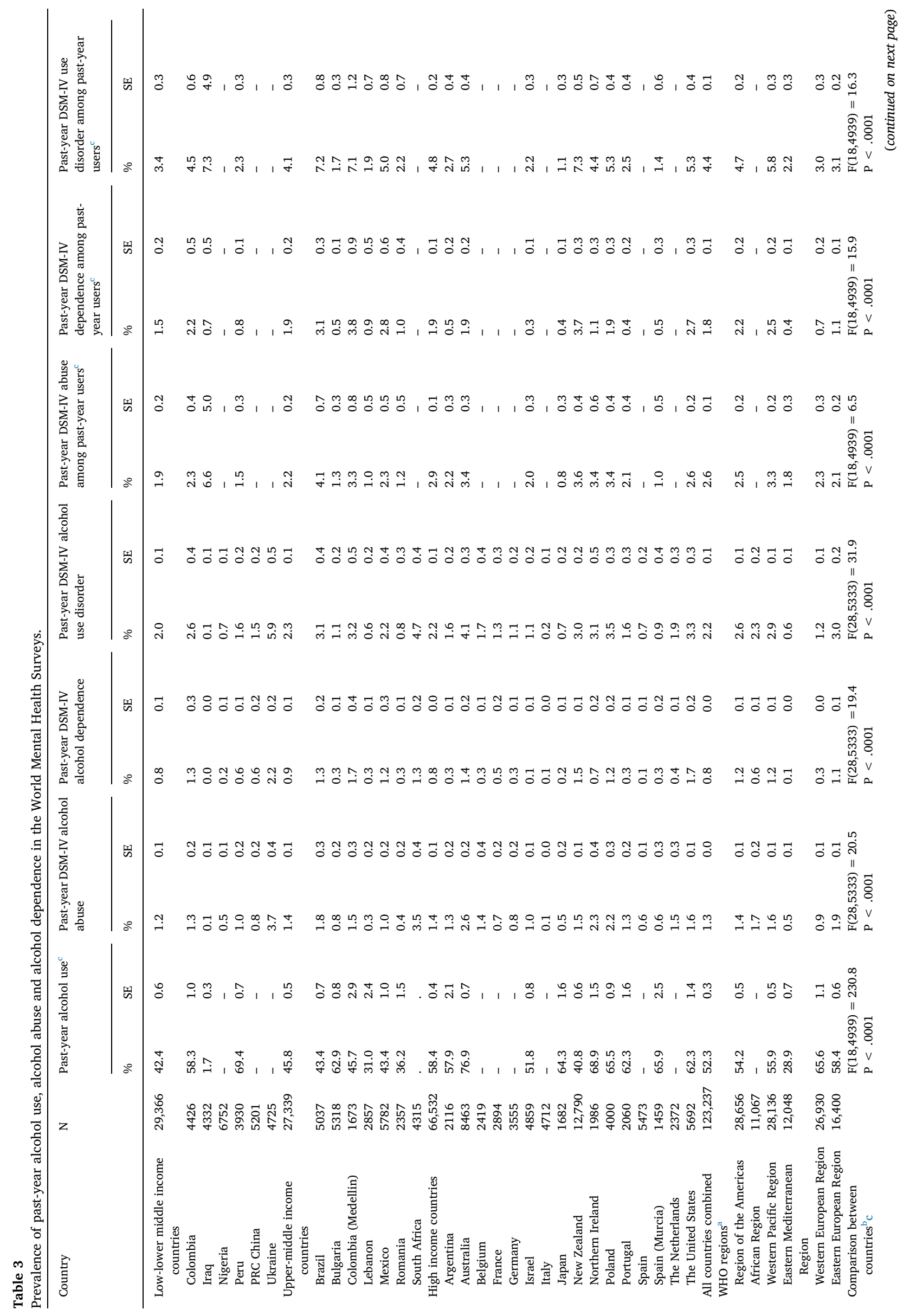




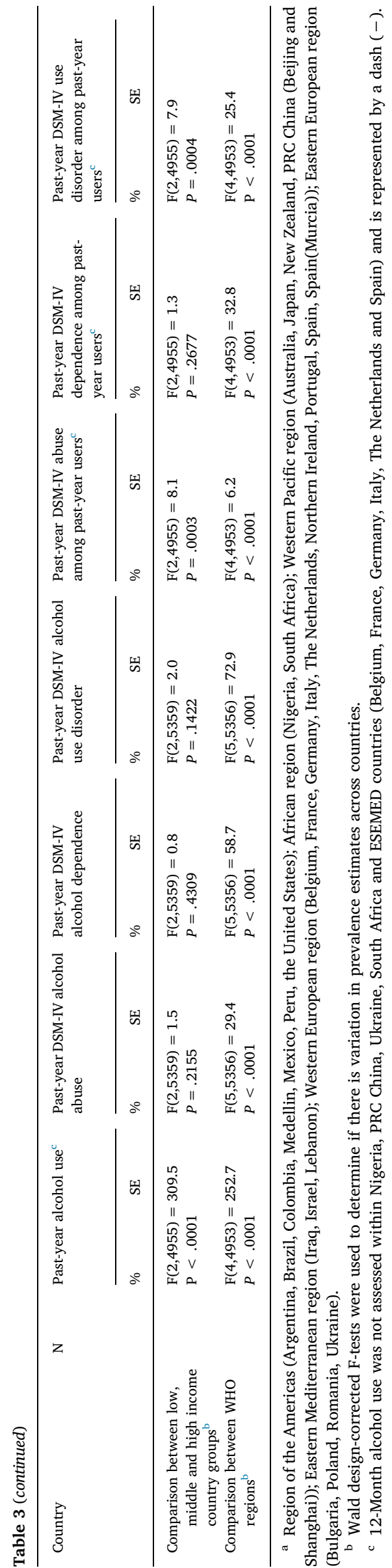

across WHO regions. The Eastern Mediterranean region had the lowest prevalence estimates among WHO regions for alcohol use (28.9\%), ALA (0.5\%), ALD (0.1\%), and AUD (0.6\%) and this pattern was consistent when conditioning upon past-year use ALA (1.8\%), ALD (0.4\%), and AUD (2.2\%). The highest unconditional past year prevalence estimates of alcohol use were from the Western European Region (65.6\%), the highest prevalence of ALA was from the Eastern Europe region (1.9\%) the highest prevalence of ALD was from the Western Pacific and Region of the Americas (1.2\%), and the highest prevalence of AUD was from the Eastern Europe region (3.0\%). When excluding alcohol abstainers, the Western Pacific surveys had the highest prevalence estimates for past year ALA (3.3\%), ALD (2.5\%) and AUD (5.8\%).

There were significant differences between income groups for ALA and AUDs but not ALD when alcohol abstainers were excluded, though there were no significant differences when they were included. Unconditional AUD prevalence ranged from $2.0 \%$ in low/lower-middle income surveys to $2.3 \%$ in upper-middle income surveys while conditional AUD prevalences ranged from $3.4 \%$ in lower income surveys to $4.8 \%$ in high income surveys.

\subsection{Remission}

Remission among people with lifetime AUD was defined at time of interview as having had more than 12 months, or at least two birthdays, since the last disorder related problem. Table 4 shows prevalence of remission at the time of interview among lifetime ALA, ALD and all AUD cases as well as among AUD cases that had at least one non-substance use mental disorders (MHD). For all conditional groups, there were significant differences in the prevalence of AUD remission across countries, income levels and regions. The average prevalence of ALA remission for all countries was $79.5 \%$ and $59.7 \%$ for ALD. The average prevalence of AUD remission was $75.2 \%$, ranging from $58.2 \%$ in Ukraine to $89.3 \%$ in Japan. When conditioning on specific disorders, the average remission prevalence was higher among ALA (79.5\%) compared to ALD (59.7\%) cases, with this same trend consistent within most survey-specific comparisons. Among those with at least one MHD, the average prevalence of AUD remission was $72.5 \%$, ranging from $47.9 \%$ in Lebanon to $94.5 \%$ in Spain.

\subsection{Gender}

Table 5 shows 12-month and lifetime prevalences for AUD by gender. The average past year prevalence of AUD for all countries was $0.9 \%$ for women, ranging from no past year cases in Iraq and Nigeria to $2.6 \%$ in Australia. The average past year prevalence for all countries was $3.6 \%$ for men ranging from $0.2 \%$ in Iraq to $11.6 \%$ in the Ukraine. Among women, the average lifetime prevalence of AUD for all countries was $3.4 \%$ ranging from no lifetime cases in Iraq to $12.1 \%$ in Australia. The average lifetime prevalence of AUDs for men was $14.1 \%$ for all countries and ranges from $1.4 \%$ in Iraq to $33.4 \%$ in Australia. In all surveys, the prevalence estimates of both lifetime and 12-month AUDs were higher for men than women.

\subsection{Disorder persistence}

Using the retrospective data on determinations of past AUD it is possible to compute an indirect indicator of disorder persistence as the proportion of lifetimes cases of ALA, ALD and AUDs among subjects who also met criteria for the same diagnosis in the 12 months before interview (Table 6). Significant differences can be seen across countries, survey income groups and WHO regions. Overall, a quarter of respondents who had ever had an AUD continued to have at least some symptoms of the disorder in the past year. For all countries combined, the rates of past-year persistence were $21.4 \%$ for ALA, 36.7\% for ALD and $25.5 \%$ for AUD. There was significant variation for all diagnoses across countries with AUD persistence ranging from 10\% in Japan to 
Table 4

Prevalence of remission from alcohol use disorders among those with specific disorders. ${ }^{\text {a }}$

\begin{tabular}{|c|c|c|c|c|c|c|c|c|}
\hline \multirow[t]{2}{*}{ Country } & \multicolumn{2}{|c|}{$\begin{array}{l}\text { Remission among DSM-IV } \\
\text { abuse cases }\end{array}$} & \multicolumn{2}{|c|}{ 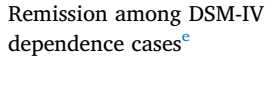 } & \multicolumn{2}{|c|}{$\begin{array}{l}\text { Remission among all DSM-IV } \\
\text { use disorder } \text { cases }^{\mathrm{e}}\end{array}$} & \multicolumn{2}{|c|}{$\begin{array}{l}\text { Remission from an AUD among those with } \\
\text { DSM-IV alcohol use disorder and at least one } \\
\text { other mental disorder }{ }^{\text {be }}\end{array}$} \\
\hline & $\%$ & SE & $\%$ & SE & $\%$ & SE & $\%$ & SE \\
\hline $\begin{array}{l}\text { Low-Lower middle income } \\
\text { countries }\end{array}$ & 74.4 & 1.5 & 46.2 & 2.7 & 67.3 & 1.4 & 62.2 & 3.2 \\
\hline Colombia & 84.0 & 2.8 & 49.5 & 5.6 & 74.7 & 3.0 & 68.6 & 4.7 \\
\hline Iraq & 78.4 & 11.9 & 93.9 & 5.2 & 82.8 & 9.8 & 60.0 & 27.1 \\
\hline Nigeria & 76.1 & 2.8 & 32.6 & 10.7 & 69.7 & 2.8 & 63.2 & 8.4 \\
\hline Peru & 76.6 & 3.9 & 62.5 & 6.2 & 73.0 & 2.6 & 73.1 & 6.2 \\
\hline PRC China & 78.5 & 3.3 & 39.9 & 8.3 & 69.9 & 3.7 & 52.7 & 11.3 \\
\hline Ukraine & 65.0 & 2.7 & 40.0 & 4.1 & 58.2 & 2.3 & 50.0 & 6.9 \\
\hline Upper-middle income countries & 71.5 & 1.7 & 59.1 & 2.9 & 67.0 & 1.5 & 65.5 & 2.5 \\
\hline Brazil & 74.0 & 3.1 & 61.3 & 3.8 & 69.8 & 2.5 & 66.1 & 3.7 \\
\hline Bulgaria & 67.3 & 5.6 & 68.1 & 7.3 & 67.5 & 4.0 & 75.1 & 7.9 \\
\hline Colombia (Medellin) & 83.4 & 3.8 & 65.3 & 7.3 & 76.6 & 3.6 & 78.0 & 4.2 \\
\hline Lebanon & 74.6 & 9.7 & 29.0 & 10.9 & 63.3 & 9.5 & 47.9 & 10.3 \\
\hline Mexico & 76.9 & 4.3 & - & - & - & - & - & - \\
\hline Romania & 82.3 & 7.0 & 38.6 & 11.5 & 72.6 & 7.4 & 56.2 & 17.5 \\
\hline South Africa & 61.1 & 3.4 & 54.0 & 6.7 & 59.4 & 3.0 & 58.4 & 4.9 \\
\hline High income countries & 82.9 & 0.7 & 67.2 & 2.0 & 80.8 & 0.8 & 77.6 & 1.5 \\
\hline Argentina & 82.4 & 2.5 & 79.0 & 7.7 & 81.9 & 2.4 & 84.5 & 4.1 \\
\hline Australia & 86.4 & 1.2 & 64.3 & 3.5 & 82.5 & 1.3 & 76.8 & 2.7 \\
\hline Belgium & 79.9 & 4.3 & 82.9 & 3.8 & 80.5 & 3.6 & 78.9 & 6.7 \\
\hline France & 87.3 & 2.7 & 66.2 & 8.7 & 82.7 & 3.5 & 88.6 & 3.9 \\
\hline Germany & 85.3 & 2.8 & 78.8 & 6.7 & 83.8 & 3.0 & 85.3 & 7.1 \\
\hline Israel & 74.1 & 3.2 & 68.4 & 10.7 & 73.5 & 3.0 & 67.1 & 6.7 \\
\hline Italy & 91.3 & 5.0 & 73.8 & 9.0 & 86.4 & 4.5 & 79.3 & 12.8 \\
\hline Japan & 92.4 & 2.8 & 66.3 & 9.2 & 89.3 & 2.9 & 91.1 & 3.9 \\
\hline New Zealand & 80.5 & 1.7 & - & - & - & - & - & - \\
\hline Northern Ireland & 79.8 & 3.4 & 69.8 & 7.2 & 77.9 & 3.1 & 78.0 & 3.7 \\
\hline Poland & 77.0 & 2.8 & 44.4 & 5.8 & 70.5 & 2.3 & 63.5 & 4.1 \\
\hline Portugal & 85.4 & 3.2 & 80.5 & 7.9 & 84.7 & 3.0 & 81.1 & 3.8 \\
\hline Spain & 81.4 & 4.0 & 82.5 & 9.9 & 81.6 & 3.9 & 94.5 & 4.0 \\
\hline Spain (Murcia) & 86.8 & 6.9 & 79.4 & 13.5 & 85.2 & 5.7 & 75.2 & 7.6 \\
\hline The Netherlands & 81.4 & 3.8 & 71.8 & 8.1 & 79.8 & 3.3 & 74.6 & 8.3 \\
\hline The United States & 80.3 & 1.6 & - & - & - & - & - & - \\
\hline All countries combined & 79.5 & 0.6 & 59.7 & 1.5 & 75.2 & 0.6 & 72.5 & 1.2 \\
\hline \multicolumn{9}{|l|}{ WHO regions ${ }^{\mathrm{c}}$} \\
\hline Region of the Americas & 79.4 & 1.2 & 60.1 & 2.7 & 74.0 & 1.4 & 72.8 & 2 \\
\hline African Region & 65.0 & 2.6 & 50.6 & 6.0 & 61.8 & 2.4 & 58.8 & 4.5 \\
\hline Western Pacific Region & 84.1 & 0.9 & 61.1 & 3.2 & 81.5 & 1.2 & 76.8 & 2.6 \\
\hline Eastern Mediterranean Region & 74.6 & 3.0 & 63.2 & 9.1 & 72.9 & 2.9 & 63.5 & 6.5 \\
\hline Western European Region & 83.3 & 1.3 & 75.7 & 2.8 & 81.8 & 1.2 & 80.8 & 1.9 \\
\hline Eastern European Region & 70.5 & 1.8 & 45.3 & 3.1 & 64.3 & 1.5 & 58.2 & 3.7 \\
\hline \multirow[t]{2}{*}{ Comparison between countries ${ }^{\mathrm{d}}$} & \multicolumn{2}{|c|}{$\mathrm{F}(28,5333)=4.3$} & \multicolumn{2}{|c|}{$\mathrm{F}(25,5070)=3.7$} & \multicolumn{2}{|c|}{$\mathrm{F}(25,5070)=6.9$} & \multicolumn{2}{|c|}{$\mathrm{F}(28,5070)=3.3$} \\
\hline & \multicolumn{2}{|c|}{$\mathrm{P}<.0001$} & \multicolumn{2}{|c|}{$\mathrm{P}<.0001$} & \multicolumn{2}{|c|}{$\mathrm{P}<.0001$} & \multicolumn{2}{|c|}{$\mathrm{P}<.0001$} \\
\hline Comparison between low, middle & \multicolumn{2}{|c|}{$\mathrm{F}(2,5359)=26.4$} & \multicolumn{2}{|c|}{$\mathrm{F}(2,5093)=17.6$} & \multicolumn{2}{|c|}{$F(2,5093)=53.4$} & \multicolumn{2}{|c|}{$\mathrm{F}(2,5093)=14.4$} \\
\hline $\begin{array}{l}\text { and high income country } \\
\text { groups }^{\mathrm{d}}\end{array}$ & \multicolumn{2}{|c|}{$\mathrm{P}<.0001$} & \multicolumn{2}{|c|}{$P<.0001$} & $\mathrm{P}<$. & & $\mathrm{P}<$. & \\
\hline Comparison between WHO & $\mathrm{F}(5,5$ & 5.7 & $\mathrm{~F}(5,5$ & & $\mathrm{F}(5,50$ & & $\mathrm{F}(5,50$ & \\
\hline regions $^{\mathrm{d}}$ & $\mathrm{P}<$ & & $\mathrm{P}<$ & & $\mathrm{P}<$. & & $\mathrm{P}<$. & \\
\hline
\end{tabular}

a Remission is defined as having reported more than 12 months, or at least two birthdays, since the last disorder related problem.

b Includes lifetime presence of any of the following: major depressive disorder, dysthymic disorder, bipolar disorder, panic disorder, generalized anxiety disorder,

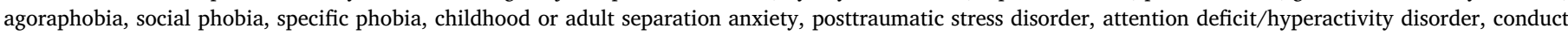
disorder, intermittent explosive disorder, and oppositional defiant disorder.

c Region of the Americas (Argentina, Brazil, Colombia, Medellin, Mexico, Peru, the United States); African region (Nigeria, South Africa); Western Pacific region

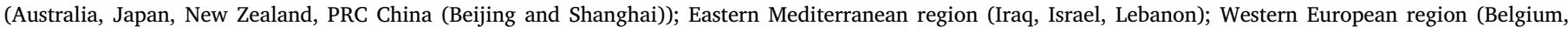
France, Germany, Italy, The Netherlands, Northern Ireland, Portugal, Spain, Spain(Murcia)); Eastern European region (Bulgaria, Poland, Romania, Ukraine).

d Wald design-corrected F-tests were used to determine if there is variation in prevalence estimates across countries.

e Remission from dependence could not be assessed in the United States, New Zealand and Mexico (see eMethods).

43.3\% in the Ukraine. Significant variation was also observed between income groups, with persistence highest for ALA among upper-middle income countries at $29.6 \%$ and for ALD and AUD among low/lowermiddle income countries at $53.8 \%$ and $34.1 \%$, respectively. Although Tables 2 and 3 show ALA as being a more prevalent disorder than ALD, the estimates presented in Table 6 show ALD to be a more persistent disorder.

\subsection{Age of onset}

Figure 1 displays AUD AOO curves among those with a lifetime AUD by survey income group. The earliest $15 \%$ of lifetime AUD cases across all survey income groups combined had onset before 18 years of age, which means that of those individuals who will develop an AUD at some time in their life, $15 \%$ will do so before age 18 . For higher 
Table 5

Prevalence of alcohol use disorders among women and men by country.

\begin{tabular}{|c|c|c|c|c|c|c|c|c|}
\hline \multirow[t]{2}{*}{ Country } & \multicolumn{2}{|c|}{$\begin{array}{l}\text { Lifetime } \\
\text { DSM-IV } \\
\text { alcohol use } \\
\text { disorder } \\
\text { among } \\
\text { women }\end{array}$} & \multicolumn{2}{|c|}{$\begin{array}{l}\text { Lifetime } \\
\text { DSM-IV } \\
\text { alcohol use } \\
\text { disorder } \\
\text { among men }\end{array}$} & \multicolumn{2}{|c|}{$\begin{array}{l}\text { Past-year } \\
\text { DSM-IV } \\
\text { alcohol use } \\
\text { disorder } \\
\text { among } \\
\text { women }\end{array}$} & \multicolumn{2}{|c|}{$\begin{array}{l}\text { Past-year } \\
\text { DSM-IV } \\
\text { alcohol use } \\
\text { disorder } \\
\text { among men }\end{array}$} \\
\hline & $\%$ & SE & & & $\%$ & SE & $\%$ & $\mathrm{SE}$ \\
\hline $\begin{array}{l}\text { Low-Lower middle } \\
\text { income countries }\end{array}$ & 1.1 & 0.1 & 10.9 & 0.4 & 0.4 & 0.1 & 3.7 & 0.2 \\
\hline Colombia & 2.3 & 0.4 & 18.0 & 1.3 & 0.5 & 0.2 & 5.1 & 0.7 \\
\hline Iraq & - & - & 1.4 & 0.5 & - & - & 0.2 & 0.2 \\
\hline Nigeria & 0.1 & 0.1 & 4.5 & 0.4 & - & - & 1.4 & 0.2 \\
\hline Peru & 0.9 & 0.2 & 10.9 & 0.7 & 0.3 & 0.1 & 2.9 & 0.3 \\
\hline PRC China & 0.5 & 0.2 & 8.5 & 0.8 & 0.2 & 0.1 & 2.6 & 0.5 \\
\hline Ukraine & 2.9 & 0.4 & 26.9 & 1.5 & 1.3 & 0.2 & 11.6 & 1.0 \\
\hline $\begin{array}{l}\text { Upper-middle income } \\
\text { countries }\end{array}$ & 2.3 & 0.2 & 12.5 & 0.4 & 0.8 & 0.1 & 4.0 & 0.3 \\
\hline Brazil & 4.0 & 0.5 & 16.4 & 1.1 & 1.2 & 0.3 & 5.3 & 0.6 \\
\hline Bulgaria & 0.6 & 0.2 & 5.9 & 0.6 & 0.3 & 0.1 & 2.0 & 0.3 \\
\hline Colombia (Medellin) & 5.3 & 0.7 & 21.4 & 2.8 & 1.4 & 0.4 & 5.3 & 1.0 \\
\hline Lebanon & 0.4 & 0.3 & 2.8 & 0.6 & 0.4 & 0.3 & 0.8 & 0.3 \\
\hline Mexico & 1.3 & 0.3 & 15.4 & 1.1 & 0.2 & 0.2 & 4.3 & 0.7 \\
\hline Romania & 0.2 & 0.1 & 6.4 & 0.6 & 0.1 & 0.1 & 1.6 & 0.5 \\
\hline South Africa & 5.0 & 0.6 & 19.0 & 1.4 & 2.0 & 0.3 & 8.0 & 0.9 \\
\hline High income countries & 4.8 & 0.1 & 16.3 & 0.3 & 1.1 & 0.1 & 3.4 & 0.1 \\
\hline Argentina & 3.0 & 0.5 & 14.1 & 1.4 & 0.7 & 0.2 & 2.6 & 0.4 \\
\hline Australia & 12.1 & 0.7 & 33.4 & 1.1 & 2.6 & 0.3 & 5.6 & 0.5 \\
\hline Belgium & 2.1 & 0.6 & 14.6 & 1.6 & 0.5 & 0.2 & 2.9 & 0.7 \\
\hline France & 2.0 & 0.3 & 12.7 & 1.0 & 0.2 & 0.1 & 2.4 & 0.5 \\
\hline Germany & 1.7 & 0.3 & 11.6 & 1.1 & 0.4 & 0.1 & 1.9 & 0.4 \\
\hline Israel & 1.1 & 0.2 & 7.8 & 0.6 & 0.3 & 0.1 & 2.0 & 0.3 \\
\hline Italy & 0.2 & 0.1 & 2.4 & 0.4 & 0.1 & 0.1 & 0.3 & 0.1 \\
\hline Japan & 2.5 & 0.7 & 12.9 & 1.3 & 0.2 & 0.1 & 1.3 & 0.4 \\
\hline New Zealand & 7.2 & 0.4 & 17.4 & 0.6 & 1.8 & 0.2 & 4.3 & 0.3 \\
\hline Northern Ireland & 5.8 & 0.6 & 21.2 & 1.8 & 1.5 & 0.3 & 4.7 & 0.9 \\
\hline Poland & 3.4 & 0.4 & 18.9 & 0.9 & 0.6 & 0.1 & 6.4 & 0.5 \\
\hline Portugal & 2.3 & 0.4 & 18.4 & 1.9 & 0.4 & 0.2 & 2.8 & 0.6 \\
\hline Spain & 1.0 & 0.2 & 6.5 & 0.8 & 0.1 & 0.0 & 1.4 & 0.3 \\
\hline Spain (Murcia) & 1.2 & 0.4 & 11.4 & 1.3 & 0.1 & 0.0 & 1.8 & 0.7 \\
\hline The Netherlands & 3.7 & 0.6 & 14.3 & 1.6 & 1.0 & 0.3 & 2.8 & 0.6 \\
\hline The United States & 7.8 & 0.5 & 20.5 & 1.0 & 1.9 & 0.3 & 4.8 & 0.4 \\
\hline $\begin{array}{l}\text { All countries combined } \\
\text { WHO regions }{ }^{\mathrm{a}}\end{array}$ & 3.4 & 0.1 & 14.1 & 0.2 & 0.9 & 0.0 & 3.6 & 0.1 \\
\hline $\begin{array}{l}\text { Region of the } \\
\text { Americas }\end{array}$ & 3.5 & 0.2 & 16.6 & 0.5 & 0.9 & 0.1 & 4.4 & 0.2 \\
\hline African Region & 2.1 & 0.3 & 10.0 & 0.6 & 0.8 & 0.1 & 3.9 & 0.3 \\
\hline $\begin{array}{l}\text { Western Pacific } \\
\text { Region }\end{array}$ & 7.3 & 0.3 & 20.2 & 0.5 & 1.7 & 0.1 & 4.2 & 0.2 \\
\hline $\begin{array}{l}\text { Eastern Mediterranean } \\
\text { Region }\end{array}$ & 0.6 & 0.1 & 4.3 & 0.3 & 0.2 & 0.1 & 1.1 & 0.2 \\
\hline $\begin{array}{l}\text { Western European } \\
\text { Region }\end{array}$ & 1.9 & 0.1 & 10.8 & 0.4 & 0.4 & 0.1 & 2.0 & 0.2 \\
\hline $\begin{array}{l}\text { Eastern European } \\
\text { Region }\end{array}$ & 1.9 & 0.2 & 15.0 & 0.5 & 0.6 & 0.1 & 5.7 & 0.3 \\
\hline
\end{tabular}

A dash indicates a zero cell count.

a Region of the Americas (Argentina, Brazil, Colombia, Medellin, Mexico, Peru, the United States); African region (Nigeria, South Africa); Western Pacific region (Australia, Japan, New Zealand, PRC China (Beijing and Shanghai)); Eastern Mediterranean region (Iraq, Israel, Lebanon); Western European region (Belgium, France, Germany, Italy, The Netherlands, Northern Ireland, Portugal, Spain, Spain(Murcia)); Eastern European region (Bulgaria, Poland, Romania, Ukraine).

percentages of AUDs, AOO generally decreased as survey income level increased. The median AOO for AUDs was 21 years in high-income survey countries, 23 years in upper-middle income countries and 24 years in low/lower-middle income countries.

\subsection{Demographics}

Consistent with previous studies, men were significantly more likely than women to have a lifetime or past year persistent AUD (Table 7). The odds for men having a lifetime AUD were 4.6 (95\% CI 4.3-4.9) times the odds for women and, among those with a lifetime AUD, the odds for a past year AUD among men were 1.2 (95\% CI 1.0-1.4) times the odds for women.

Based on age at interview, younger cohorts were more likely to have a lifetime AUD and past year AUD persistence, with respondents aged 18-29 years having the highest odds for both lifetime (OR 10.4, 95\% CI 9.2-11.7) and persistent past-year (OR 3.1, 95\% CI 2.2-4.3) AUD compared to those aged 60 or over at time of interview. Employment status was significantly associated with development and persistence of AUD, with students less likely to develop a lifetime AUD (OR $0.8,95 \%$ CI 0.7-1.0) but significantly more likely to persist once developing the disorder (OR 1.5, 95\% CI 1.1-2.1) compared to those in employment. Marital status was significantly associated with lifetime and past year persistence of AUD, with divorced, separated or widowed respondents associated with the greatest odds of lifetime AUD (OR 1.6, 95\% CI 1.5-1.7) and the never-married at elevated odds of both lifetime (OR 1.3, 95\% CI 1.2-1.4) and persistent past-year AUD (OR 1.9, 95\% CI 1.7-2.2) compared to those married at time of interview. Education level was significantly associated with lifetime AUD and past year AUD among lifetime cases, with a general trend of an inverse association between educational attainment and likelihood of an AUD. Household income was a significant predictor of lifetime AUD, with those from low (OR 1.2, 95\% CI 1.2-1.3) and low-average (OR 1.1, 95\% CI 1.1-1.2) income households significantly more likely to develop the disorder compared to persons living in high income households.

\subsection{Onset relative to other mental disorders}

AUDs are highly comorbid with MHD (Table 8). Among respondents with a lifetime AUD, $43.9 \%$ had at least one other lifetime MHD, and among those who had ever experienced any MHD, 17.9\% had a lifetime AUD. Of those with a past year AUD, 58.6\% had at least one other lifetime MHD and $42.9 \%$ had at least one other MHD in the same 12month period (Appendix Table 1). Regarding the ordering of onset of these disorders, the MHD most often preceded the onset of the AUD, as was the case for dysthymia, agoraphobia, social phobia, specific phobias, separation anxiety, ADHD, conduct disorder, intermittent explosive disorder (IED) and oppositional defiant disorder (ODD). The exceptions were bipolar disorder, panic disorder, and generalized anxiety disorder (GAD) where no significant trend in temporal order of onset was observed, and major depressive disorder (MDD), where AUD onset most often occurred prior to disorder onset.

\section{Discussion}

The mean lifetime prevalence of AUDs in the 29 WMH surveys combined was $8.6 \%$, ranging from $0.7 \%$ in Iraq to $22.7 \%$ in Australia. The combined mean 12-month AUD prevalence was $2.2 \%$, ranging from $0.1 \%$ in Iraq to $5.9 \%$ in the Ukraine. This is a high level of disorder prevalence given the substantial health and economic burdens associated with AUDs (Moskalewicz, Room, \& Thom, 2016; Peacock, Leung, Larney, et al., 2018; Webb, Bromet, Gluzman, et al., 2005). Although the AUD prevalence estimates range widely across the WMH countries, these estimates and the variations are consistent with findings from other national and regional surveys (Mathers \& Ayuso-Mateos, 2003; Adlaf, Begin, \& Sawka, 2005; Bromet, Gluzman, Paniotto, et al., 2005; Chen \& Yin, 2008; Cochrane, Chen, Conigrave, et al., 2003; Hasin, Stinson, Ogburn, et al., 2007; Lukassen \& Beaudet, 2005; Rehm, Room, Van Den Brink, et al., 2005; Taylor, 2007; Ulaş, Binbay, Kırlı, et al., 2017; Wittchen \& Jacobi, 2005). There was also a relatively wide crossnational range of AUD prevalence estimates among lifetime non-abstainers. The combined lifetime prevalence of AUDs among non-abstainers was $10.7 \%$, ranging from $1.7 \%$ in Italy to $28.3 \%$ in South Africa and the combined 12-month prevalence of AUDs among non-abstainers 
Table 6

Prevalence of past-year alcohol use disorders among those with lifetime alcohol use disorders in the World Mental Health Surveys.

\begin{tabular}{|c|c|c|c|c|c|c|c|}
\hline \multirow[t]{2}{*}{ Country } & \multirow[t]{2}{*}{$\mathrm{N}$} & \multicolumn{2}{|c|}{$\begin{array}{l}\text { Past-year DSM-IV abuse among } \\
\text { lifetime DSM-IV alcohol abuse cases }\end{array}$} & \multicolumn{2}{|c|}{$\begin{array}{l}\text { Past-year DSM-IV dependence among } \\
\text { lifetime DSM-IV alcohol dependence cases }\end{array}$} & \multicolumn{2}{|c|}{$\begin{array}{l}\text { Past-year DSM-IV use disorder among } \\
\text { lifetime DSM-IV alcohol use disorder cases }\end{array}$} \\
\hline & & $\%$ & SE & $\%$ & SE & $\%$ & SE \\
\hline Low-Lower middle income countries & 29,366 & 27.5 & 1.6 & 53.8 & 2.8 & 34.1 & 1.4 \\
\hline Colombia & 4426 & 19.1 & 3.2 & 50.6 & 6.3 & 27.6 & 3.2 \\
\hline Iraq & 4332 & 21.6 & 11.9 & 6.1 & 5.2 & 17.2 & 9.8 \\
\hline Nigeria & 6752 & 24.8 & 2.9 & 67.4 & 10.7 & 31.0 & 2.9 \\
\hline Peru & 3930 & 24.2 & 3.5 & 37.5 & 6.2 & 27.6 & 2.3 \\
\hline PRC China & 5201 & 22.8 & 3.4 & 60.1 & 8.3 & 31.1 & 3.7 \\
\hline Ukraine & 4725 & 37.1 & 2.8 & 60.0 & 4.1 & 43.3 & 2.3 \\
\hline Upper-middle income countries & 27,339 & 29.6 & 1.8 & 38.3 & 2.7 & 32.5 & 1.5 \\
\hline Brazil & 5037 & 27.1 & 3.2 & 41.2 & 3.4 & 31.8 & 2.5 \\
\hline Bulgaria & 5318 & 35.4 & 5.4 & 31.9 & 7.3 & 34.3 & 4.0 \\
\hline Colombia (Medellin) & 1673 & 18.7 & 4.2 & 36.5 & 7.5 & 25.4 & 3.8 \\
\hline Lebanon & 2857 & 25.4 & 9.7 & 71.0 & 10.9 & 36.7 & 9.5 \\
\hline Mexico & 5782 & 23.6 & 4.4 & 31.5 & 5.7 & 27.3 & 3.9 \\
\hline Romania & 2357 & 17.6 & 6.6 & 50.3 & 13.1 & 24.8 & 7.3 \\
\hline South Africa & 4315 & 39.9 & 3.3 & 45.8 & 6.6 & 41.3 & 3.0 \\
\hline High income countries & 66,532 & 17.8 & 0.7 & 31.8 & 1.3 & 21.4 & 0.7 \\
\hline Argentina & 2116 & 18.1 & 2.6 & 26.6 & 7.5 & 19.3 & 2.5 \\
\hline Australia & 8463 & 14.1 & 1.2 & 36.2 & 3.5 & 18.0 & 1.4 \\
\hline Belgium & 2419 & 20.7 & 4.2 & 19.2 & 4.0 & 20.4 & 3.6 \\
\hline France & 2894 & 13.4 & 3.0 & 33.8 & 8.7 & 17.9 & 3.6 \\
\hline Germany & 3555 & 15.4 & 3.1 & 21.2 & 6.7 & 16.8 & 3.2 \\
\hline Israel & 4859 & 25.9 & 3.2 & 31.6 & 10.7 & 26.5 & 3.0 \\
\hline Italy & 4712 & 8.7 & 5.0 & 26.2 & 9.0 & 13.6 & 4.5 \\
\hline Japan & 1682 & 7.6 & 2.8 & 27.8 & 8.6 & 10.0 & 2.7 \\
\hline New Zealand & 12,790 & 19.7 & 1.8 & 32.3 & 2.1 & 24.6 & 1.5 \\
\hline Northern Ireland & 1986 & 21.7 & 3.8 & 29.6 & 7.1 & 23.2 & 3.5 \\
\hline Poland & 4000 & 25.0 & 2.8 & 56.0 & 5.8 & 31.3 & 2.3 \\
\hline Portugal & 2060 & 15.1 & 3.3 & 19.5 & 7.9 & 15.7 & 3.1 \\
\hline Spain & 5473 & 19.5 & 4.0 & 17.5 & 9.9 & 19.2 & 3.9 \\
\hline Spain (Murcia) & 1459 & 13.2 & 6.9 & 20.6 & 13.5 & 14.8 & 5.7 \\
\hline The Netherlands & 2372 & 20.0 & 3.9 & 28.2 & 8.1 & 21.3 & 3.4 \\
\hline The United States & 5692 & 20.9 & 1.6 & 27.7 & 2.5 & 23.9 & 1.6 \\
\hline All countries combined & 123,237 & 21.4 & 0.6 & 36.7 & 1.1 & 25.5 & 0.6 \\
\hline \multicolumn{8}{|l|}{ WHO regions $\mathrm{s}^{\mathrm{a}}$} \\
\hline Region of the Americas & 28,656 & 22.0 & 1.2 & 34.6 & 1.9 & 26.6 & 1.1 \\
\hline African Region & 11,067 & 36.0 & 2.6 & 49.2 & 5.9 & 38.9 & 2.4 \\
\hline Western Pacific Region & 28,136 & 16.3 & 1.0 & 35.1 & 1.8 & 21.2 & 0.9 \\
\hline Eastern Mediterranean Region & 12,048 & 25.4 & 3.0 & 36.8 & 9.1 & 27.1 & 2.9 \\
\hline Western European Region & 26,930 & 17.5 & 1.3 & 24.5 & 2.8 & 18.9 & 1.3 \\
\hline Eastern European Region & 16,400 & 31.5 & 1.9 & 54.2 & 3.1 & 37.1 & 1.6 \\
\hline Comparison between countries ${ }^{\mathrm{b}}$ & & \multicolumn{2}{|c|}{$\begin{array}{l}\mathrm{F}(28,5333)=4.5 \\
\mathrm{P}<.0001\end{array}$} & \multicolumn{2}{|c|}{$\mathrm{F}(28,5333)=3.8 \mathrm{P}<.0001$} & \multicolumn{2}{|c|}{$\mathrm{F}(28,5333)=6.5 \mathrm{P}<.0001$} \\
\hline \multicolumn{2}{|l|}{$\begin{array}{l}\text { Comparison between low, middle and } \\
\text { high income country groups }\end{array}$} & \multicolumn{2}{|c|}{$\begin{array}{l}\mathrm{F}(2,5359)=29.7 \\
\mathrm{P}<.0001\end{array}$} & \multicolumn{2}{|c|}{$\mathrm{F}(2,5359)=21.8 \mathrm{P}<.0001$} & \multicolumn{2}{|c|}{$\mathrm{F}(2,5359)=46.2 \mathrm{P}<.0001$} \\
\hline Comparison between WHO regions ${ }^{\mathrm{b}}$ & & \multicolumn{2}{|c|}{$\begin{array}{l}F(5,5356)=17.2 \\
P<.0001\end{array}$} & \multicolumn{2}{|c|}{$\mathrm{F}(5,5356)=11.0 P<.0001$} & \multicolumn{2}{|c|}{$\mathrm{F}(5,5356)=25.0 \mathrm{P}<.0001$} \\
\hline
\end{tabular}

a Region of the Americas (Argentina, Brazil, Colombia, Medellin, Mexico, Peru, the United States); African region (Nigeria, South Africa); Western Pacific region

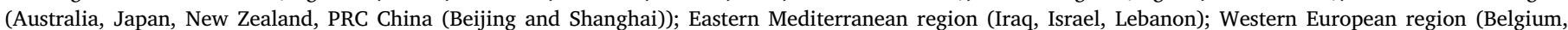
France, Germany, Italy, The Netherlands, Northern Ireland, Portugal, Spain, Spain(Murcia)); Eastern European region (Bulgaria, Poland, Romania, Ukraine).

b Wald design-corrected F-tests were used to determine if there is variation in prevalence estimates across countries.

was $4.4 \%$ ranging from $1.1 \%$ in Japan to $7.3 \%$ in Iraq and New Zealand. Both AUD remission and persistence were common. The average prevalence of remission for at least the last year was 79.5\% for ALA, 59.7\% for ALD, and $75.2 \%$ for AUD while the average prevalence of past-year persistence was $21.4 \%$ for ALA, 36.7\% for ALD and 25.5\% for AUD.

The rank ordering across countries of lifetime prevalence estimates in the total population and non-abstainers was the same or similar for most countries but notably dissimilar in a few countries. For example, among all WMH surveys, Iraq had the lowest population prevalence of both past year and lifetime AUDs but for the subgroup of non-lifetime abstainers, Iraq had the highest 12-month prevalence and the third highest prevalence of lifetime AUDs. Iraq's general population had a relatively low risk for AUDs which may suggest that AUDs are not a significant concern in Iraq. However, among those who had ever used alcohol, the risk for AUDs was comparatively high (19.2\%). A large difference was also found in South Africa comparing the AUD prevalence in the general population (11.5\%) and among users (28.3\%).

There were significant differences in AUD prevalence across the WHO Regions. The Eastern Mediterranean region which had the lowest per capita alcohol consumption and the lowest proportion of drinkers also had the lowest past year and lifetime AUD prevalences. Presumably low consumption and high abstention are limiting factors on the development of AUDs in the general population of a country or region. Supporting this, the range of AUD prevalences across the WHO Regions narrows when considering only lifetime alcohol non-abstainers. However, the limiting effect of low consumption and high abstention may exert more influence at lower levels of alcohol consumption. While the annual per capita alcohol consumption of both France and Australia is relatively high at $\mathbf{1 2 . 2}$ litersl of pure alcohol (World Health Organization, Management of Substance Abuse Unit, 2014), the lifetime prevalence of AUDs was $7.1 \%$ for France and $22.7 \%$ for Australia. 


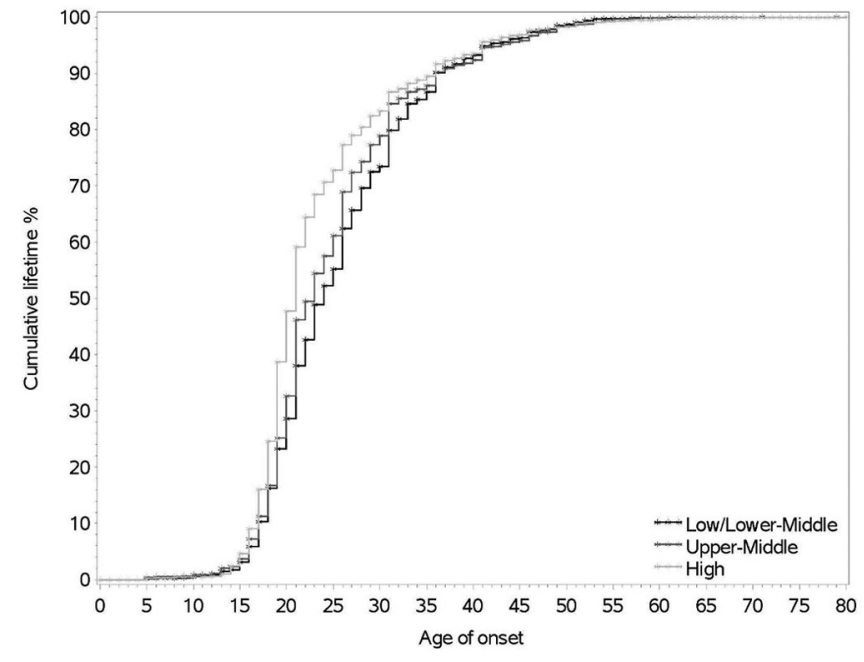

Figure 1. Age of DSM-IV alcohol use disorder onset distributions among those with a diagnosis by survey income groups.

There are probably a number of contributors to this difference, but one possible factor might be a difference in the prevalence of heavy episodic or binge drinking which has been found to have relatively more severe consequences and association with AUDs than temperate patterns (Rehm, Rehn, Room, et al., 2003). Studies have found that France has the lowest level of binge drinking in Europe(Leifman, 2002) while Australia has comparatively high rates (Toumbourou, Beyers, Catalano, et al., 2005; Yang, Zhao, \& Srivastava, 2016). Some view heavy episodic drinking as a primary indicator of severe alcohol use problems and have recommended that AUDs, particularly dependence, be measured via heavy drinking over time with diagnosis thresholds set in average per day consumption of alcohol(Rehm, 2016; Rehm \& Room, 2017; Wood, Kaptoge, Butterworth, et al., 2018). The WMH findings suggest that alcohol consumption measures may enhance understanding of psychiatric epidemiological findings.

Other potentially limiting contextual factors may account for and possibly reflect some of the cross-national variation in prevalence of AUDs. Some of these may include social-cultural influences(Gordon, Heim, \& Macaskill, 2012; Savic, Room, Mugavin, et al., 2016) such as parental involvement, drinking culture, and stigma while other factors may be more policy related(Babor, Caetano, Casswell, et al., 2010; Simpura, Karlsson, \& Leppänen, 2002) such as legal sanctions, enforcement of prohibitions and alcohol availability, all of which may be subject to change over time. The possible influence of these factors is important to interpretation of the country AUD prevalences and to inferences about explanations for the varying AUD prevalences. However, interpretations should not assume simple causality and speculations must be cautious regarding how prevalences might change if different

Table 7

Bivariate associations between sociodemographic correlates and DSM-IV alcohol use disorder.

\begin{tabular}{|c|c|c|c|c|}
\hline \multirow[t]{2}{*}{ Prevalence of AUD according to... } & \multicolumn{2}{|c|}{ Lifetime DSM-IV alcohol use disorder } & \multicolumn{2}{|c|}{ Past-year DSM-IV alcohol use disorder among lifetime alcohol use disorder ${ }^{\mathrm{b}}$} \\
\hline & $\%(\mathrm{SE})$ & OR $(95 \% \mathrm{CI})$ & $\%$ (SE) & OR $(95 \% \mathrm{CI})$ \\
\hline \multicolumn{5}{|l|}{ Gender } \\
\hline Male & $14.1(0.2)$ & $4.6^{*}(4.3-4.9)$ & $25.6(0.6)$ & $1.2 *(1.0-1.3)$ \\
\hline Female & $3.4(0.1)$ & 1 & $25.3(1.1)$ & 1 \\
\hline F-value $[\mathrm{p}]$ & & $2608.0^{*}[<0.001]$ & & $5.7 *[0.017]$ \\
\hline \multicolumn{5}{|l|}{ Age-cohort } \\
\hline $18-29$ & $9.1(0.2)$ & $10.4 *(9.2-11.7)$ & $41.0(1.2)$ & $3.1 *(2.2-4.3)$ \\
\hline $30-44$ & $9.8(0.2)$ & $6.0 *(5.5-6.6)$ & $23.6(0.9)$ & $1.8 *(1.3-2.4)$ \\
\hline $45-59$ & $9.4(0.2)$ & $3.4 *(3.1-3.8)$ & $17.5(0.9)$ & $1.7 *(1.3-2.3)$ \\
\hline $60+$ & $4.6(0.2)$ & 1 & $7.8(0.8)$ & 1 \\
\hline F-value $[\mathrm{p}]$ & & $551.5^{*}[<0.001]$ & & $22.0^{*}[<0.001]$ \\
\hline \multicolumn{5}{|l|}{ Employment status } \\
\hline Student & $5.9(0.5)$ & $0.8^{*}(0.7-1.0)$ & $40.4(3.7)$ & $1.5^{*}(1.1-2.1)$ \\
\hline Homemaker & $3.6(0.2)$ & $0.9^{*}(0.8-1.0)$ & $22.4(2.0)$ & $1.0(0.8-1.3)$ \\
\hline Retired & $4.7(0.2)$ & $0.8^{*}(0.7-0.9)$ & $10.7(1.2)$ & $0.9(0.7-1.1)$ \\
\hline Other & $11.6(0.4)$ & $1.5^{*}(1.4-1.6)$ & $34.3(1.6)$ & $1.4 *(1.2-1.6)$ \\
\hline Employed & $10.2(0.2)$ & 1 & $24.9(0.6)$ & 1 \\
\hline F-value $[\mathrm{p}]$ & & $36.8^{*}[<0.001]$ & & $5.4 *[<0.001]$ \\
\hline \multicolumn{5}{|l|}{ Marital status } \\
\hline Never married & $10.6(0.3)$ & $1.3^{*}(1.2-1.4)$ & $38.4(1.1)$ & $1.9 *(1.7-2.2)$ \\
\hline Divorced/separated/widowed & $9.2(0.3)$ & $1.6^{*}(1.5-1.7)$ & $19.5(1.2)$ & $1.1(0.9-1.3)$ \\
\hline Currently married & $7.6(0.1)$ & 1 & $19.7(0.7)$ & 1 \\
\hline F-value $[\mathrm{p}]$ & & $80.9^{* *}[<0.001]$ & & $44.1 *[<0.001]$ \\
\hline \multicolumn{5}{|l|}{ Education level } \\
\hline No education & $2.4(0.3)$ & $1.2(0.9-1.6)$ & $35.1(6.3)$ & $2.5 *(1.3-5.0)$ \\
\hline Some primary & $7.1(0.4)$ & $1.7^{*}(1.5-2.0)$ & $22.0(1.9)$ & $1.3(0.9-1.7)$ \\
\hline Finished primary & $6.4(0.3)$ & $1.7^{*}(1.5-1.9)$ & $25.5(2.1)$ & $1.3(1.0-1.8)$ \\
\hline Some secondary & $9.9(0.2)$ & $1.7^{*}(1.6-1.9)$ & $27.2(1.2)$ & $1.3^{*}(1.1-1.6)$ \\
\hline Finished secondary & $8.9(0.2)$ & $1.4^{*}(1.2-1.5)$ & $26.4(1.0)$ & $1.2(1.0-1.4)$ \\
\hline Some college & $11.5(0.3)$ & $1.4^{*}(1.3-1.5)$ & $26.5(1.3)$ & $1.3 *(1.1-1.6)$ \\
\hline Finished college & $7.7(0.3)$ & 1 & $22.5(1.3)$ & 1 \\
\hline F-value $[\mathrm{p}]$ & & $25.7^{*}[<0.001]$ & & $2.2 *[0.042]$ \\
\hline \multicolumn{5}{|l|}{ Household income } \\
\hline Low & $9.9(0.2)$ & $1.2 *(1.2-1.3)$ & $27.9(1.1)$ & $1.3^{*}(1.1-1.5)$ \\
\hline Low-average & $9.5(0.2)$ & $1.1^{*}(1.1-1.2)$ & $25.5(1.2)$ & $1.1(1.0-1.3)$ \\
\hline High-average & $9.2(0.2)$ & $1.0(1.0-1.1)$ & $25.1(1.1)$ & $1.1(0.9-1.3)$ \\
\hline High & $10.2(0.3)$ & 1 & $23.8(1.1)$ & 1 \\
\hline F-value $[\mathrm{p}]$ & & $15.0^{*}[<0.001]$ & & $2.5[0.060]$ \\
\hline
\end{tabular}

* Significant at the 0.05 level, 2-sided test.

${ }^{a}$ Estimates are based on discrete-time logistic regression analyses controlling for age-cohorts, gender, person-years and country.

b Estimates are based on logistic regression model adjusted for time since AUD onset, gender and country. 


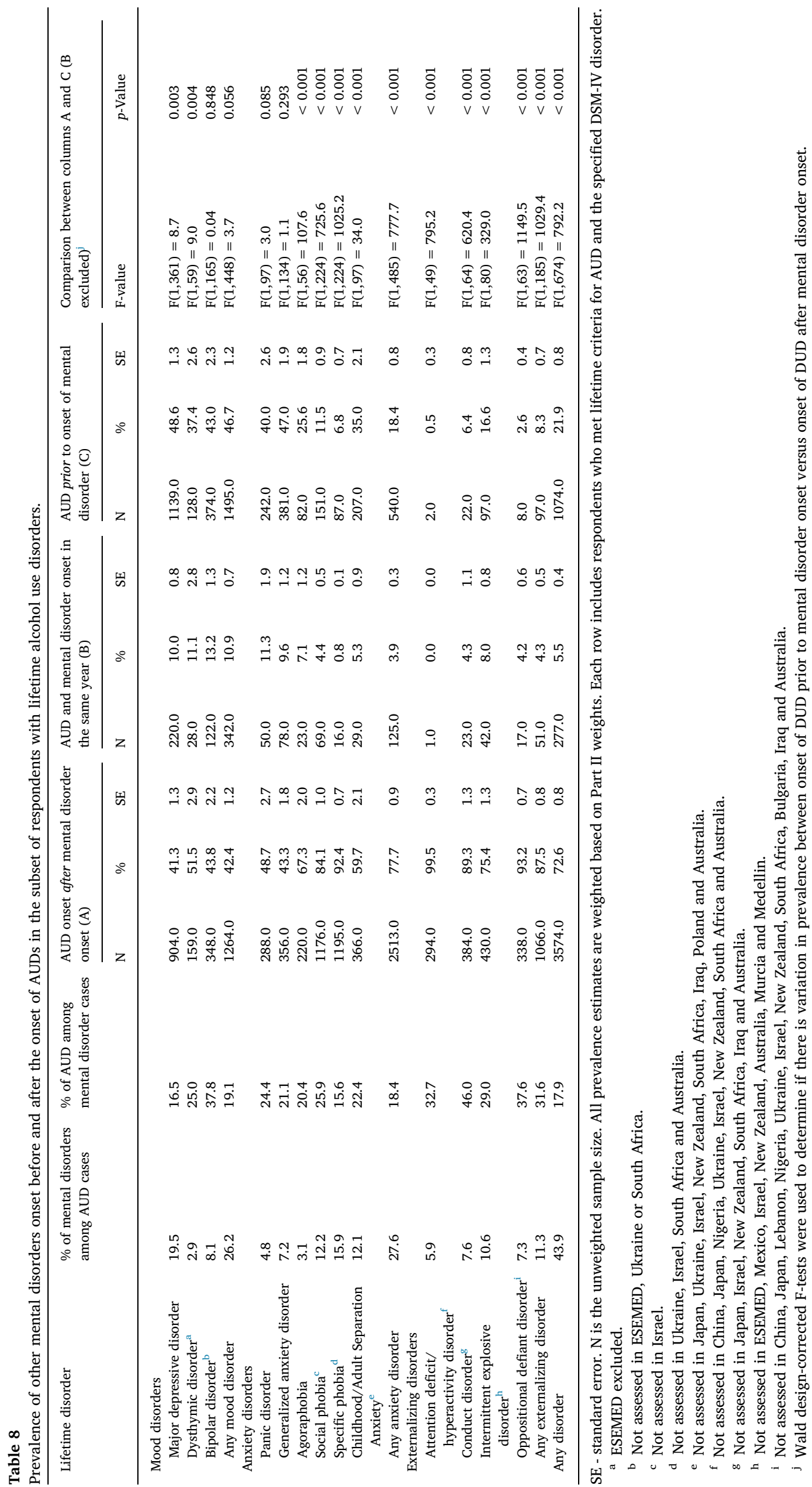


environmental and social conditions were instituted.

There is evidence that in Europe, North America, and Australia adolescent levels of drinking have declined in recent years, perhaps in relation to changing socio-environmental factors(De Looze, Raaijmakers, Ter Bogt, et al., 2015; Group, 2016; Kuntsche, Kuntsche, Knibbe, et al., 2011; Livingston, 2014; Miech, Johnston, O'malley, et al., 2017). However, alcohol consumption is stable or increasing in other regions(World Health Organization, 2018) and there are reports that abstaining or moderate alcohol using adolescents often considerably increase consumption to heavy drinking as young adults (Jager, Keyes, \& Schulenberg, 2015; White, Castle, Chen, et al., 2015; World Health Organization, 2018) and that middle-age and older adults may be increasingly engaging in binge drinking(Grucza, Sher, Kerr, et al., 2018).

Despite changes in alcohol use in different ages and regions, varying sociocultural environments, and the range of AUD prevalences, the multinational WMH results confirm a number of well-documented clinical and epidemiological findings from more local studies. For example, AUD prevalences are much higher for men than women(Obot \& Room, 2005). Risk for onset of AUD begins in adolescence with half of all lifetime cases beginning by age 23 although new onsets continue through later life(Ystrom, Kendler, \& Reichborn-Kjennerud, 2014). Being married(Leonard \& Rothbard, 1999) and more educated(Barr, Salvatore, Maes, et al., 2016) is associated with lower risk for AUD. Comorbidity with other mental disorders is common(Lai, Cleary, Sitharthan, et al., 2015) and mental health disorders often precede AUDs(Swendsen, Conway, Degenhardt, et al., 2010). Despite the harms and impairments associated with AUDs, there is a low prevalence of treatment(Grant, Goldstein, Saha, et al., 2015). The consistency of the patterns of AUDs and correlates across the surveyed countries provides an informative perspective on the relatively consistent nature of AUDs. AUD prevalences were much higher for men than women with the odds for men having a lifetime AUD being 4.6 times the odds for women. Risk for onset of AUD began in adolescence with $15 \%$ of all lifetime cases developing before age 18 although new onsets continued through later life. Being older at time of interview, being married, being more educated, and having a higher household income were all associated with a lower risk for AUD and for AUD persistence.

The WMH findings also corroborate and extend previous research on AUD - MHD comorbidities (Grant et al., 2015; Grant, Stinson, Dawson, et al., 2004; Jan-Llopis \& Matytsina, 2006; Lai et al., 2015; Merikangas, Mehta, Molnar, et al., 1998). Comorbidity with MHDs is common with $43.9 \%$ of individuals with a lifetime AUD having had at least one lifetime MHD. Among respondents with a lifetime MHD, $17.9 \%$ had a lifetime AUD. For most of the MHD categories considered (dysthymia, all phobias, separation anxiety, ADHD, conduct disorder, IED, and ODD) when there were MHD - AUD comorbidities, the onset of the MHD most often preceded the onset of the AUD. No significant trends in order of onset were observed for bipolar disorder, panic disorder, and GAD. The onset of AUD most often preceded the onset of only one disorder, MDD.

Onsets of MHD and AUD disorders are often not discrete events occurring at a single point in time and developing symptoms of comorbid disorders may reciprocally influence each other(Glantz, 1992; Glantz \& Leshner, 2000). This complicates assessment of the exact temporal order of the onset of emerging disorders. In addition, research suggests that AUDs and mood, anxiety and other impulse-control related mental disorders may share common underlying influences or pathways (Hasin et al., 2007; Kessler, Ormel, Petukhova, et al., 2011). There is growing interest in characterizations of mental illness that rely on dimensional rather than categorical frameworks(Caspi, Houts, Belsky, et al., 2014; Conway, Forbes, Forbush, et al., 2019; Kotov, Krueger, Watson, et al., 2017). Proposals such as these, most notably the Hierarchical Taxonomy of Psychopathology - HiTOP, are in the early stages of formulation and empirical validation but might facilitate understanding of comorbidities, underlying influences, and common transdiagnostic factors. The cross-national findings of prevalent comorbidities in the WMH surveys lend support for further explorations of dimensional approaches. In addition, the WMH findings corroborate local findings and affirm the potential value of further understanding of MHD - SUD comorbidities which is planned for future WMH research.

Limitations of the WMH surveys must be considered. As data come from 27 countries there is not a full representation of all regions, income levels and other country characteristics. Response rates and the year in which the surveys were administered varied across surveys, and cross-national differences in willingness to disclose personal information about alcohol use and associated problems are possible. The respondent information is subject to the limitations of retrospective reporting. The WMH surveys rely solely on household surveys. Data from subgroups that may differ from the larger national populations in terms of AUD prevalences and correlates were not included such as the homeless, people in jails, prisons, hospitals, halfway houses, SUD inpatient treatment facilities, or living on military bases. Although the WMH sampling does not include individuals who were residing in inpatient treatment facilities at the time of the interview, the sampling does not exclude individuals who were either in outpatient treatment at the time of the interview or who received either outpatient or inpatient treatment at any time prior to the interview. Nevertheless, if the WMH had specifically included current clinical AUD samples it is likely that more severe cases would have been identified(Rehm, Allamani, Aubin, et al., 2015).

\section{Funding acknowledgements}

The World Health Organization World Mental Health (WMH) Survey Initiative is supported by the United States National Institute of Mental Health (NIMH; R01 MH070884), the John D. and Catherine T. MacArthur Foundation, the Pfizer Foundation, the United States Public Health Service (R13-MH066849, R01-MH069864, and R01 DA016558), the Fogarty International Center (FIRCA R03-TW006481), the Pan American Health Organization, Eli Lilly and Company, Ortho-McNeil Pharmaceutical Inc., GlaxoSmithKline, and Bristol-Myers Squibb. This study was supported by an Australian National Health and Medical Research Council (NHMRC) project grant (APP1081984). We thank the staff of the WMH Data Collection and Data Analysis Coordination Centres for assistance with instrumentation, fieldwork, and consultation on data analysis. None of the funders had any role in the design, analysis, interpretation of results, or preparation of this paper. The views and opinions expressed in this report are those of the authors and should not be construed to represent the views of the World Health Organization, other sponsoring organizations, agencies, or governments. The 2007 Australian National Survey of Mental Health and Wellbeing is funded by the Australian Government Department of Health and Ageing. The Argentina survey - Estudio Argentino de Epidemiología en Salud Mental (EASM) - was supported by a grant from the Argentinian Ministry of Health (Ministerio de Salud de la Nación). The São Paulo Megacity Mental Health Survey is supported by the State of São Paulo Research Foundation (FAPESP) Thematic Project Grant 03/00204-3. The Bulgarian Epidemiological Study of common mental disorders EPIBUL is supported by the Ministry of Health and the National Center for Public Health Protection. The Chinese World Mental Health Survey Initiative is supported by the Pfizer Foundation. The Colombian National Study of Mental Health (NSMH) is supported by the Ministry of Social Protection. The Mental Health Study Medellín - Colombia was carried out and supported jointly by the Center for Excellence on Research in Mental Health (CES University) and the Secretary of Health of Medellín. The ESEMeD project is funded by the European Commission (Contracts QLG5-1999-01042; SANCO 2004123, and EAHC 20081308), (the Piedmont Region (Italy)), Fondo de Investigación Sanitaria, Instituto de Salud Carlos III, Spain (FIS 00/ 0028), Ministerio de Ciencia y Tecnología, Spain (SAF 2000-158-CE), Departament de Salut, Generalitat de Catalunya, Spain, DIUE de la 
Generalitat de Catalunya (2017 SGR 452; 2014 SGR 748), Instituto de Salud Carlos III (CIBER CB06/02/0046, RETICS RD06/0011 REM-TAP), and other local agencies and by an unrestricted educational grant from GlaxoSmithKline. Implementation of the Iraq Mental Health Survey (IMHS) and data entry were carried out by the staff of the Iraqi MOH and MOP with direct support from the Iraqi IMHS team with funding from both the Japanese and European Funds through United Nations Development Group Iraq Trust Fund (UNDG ITF). The Israel National Health Survey is funded by the Ministry of Health with support from the Israel National Institute for Health Policy and Health Services Research and the National Insurance Institute of Israel. The World Mental Health Japan (WMHJ) Survey is supported by the Grant for Research on Psychiatric and Neurological Diseases and Mental Health (H13SHOGAI-023, H14-TOKUBETSU-026, H16-KOKORO-013, H25SEISHIN-IPPAN-006) from the Japan Ministry of Health, Labour and Welfare. The Lebanese Evaluation of the Burden of Ailments and Needs Of the Nation (L.E.B.A.N.O.N.) is supported by the Lebanese Ministry of Public Health, the WHO (Lebanon), National Institute of Health / Fogarty International Center (R03 TW006481-01), anonymous private donations to IDRAAC, Lebanon, and unrestricted grants from, Algorithm, AstraZeneca, Benta, Bella Pharma, Eli Lilly, Glaxo Smith Kline, Lundbeck, Novartis, OmniPharma, Pfizer, Phenicia, Servier, UPO. The Mexican National Comorbidity Survey (MNCS) is supported by The National Institute of Psychiatry Ramon de la Fuente (INPRFMDIES - 19 - 4280) and by the National Council on Science and Technology (CONACyT-G30544- H), with supplemental support from the Pan American Health Organization (PAHO). Te Rau Hinengaro: The New Zealand Mental Health Survey (NZMHS) is supported by the New Zealand Ministry of Health, Alcohol Advisory Council, and the Health Research Council. The Nigerian Survey of Mental Health and Wellbeing (NSMHW) is supported by the WHO (Geneva), the WHO (Nigeria), and the Federal Ministry of Health, Abuja, Nigeria. The Northern Ireland Study of Mental Health was funded by the Health \& Social Care Research \& Development Division of the Public Health Agency. The Peruvian World Mental Health Study was funded by the National Institute of Health of the Ministry of Health of Peru. The Polish project Epidemiology of Mental Health and Access to Care -EZOP Project (PL 0256) was supported by Iceland, Liechtenstein and Norway through funding from the EEA Financial Mechanism and the Norwegian Financial Mechanism. EZOP project was cofinanced by the Polish Ministry of Health. The Portuguese Mental Health Study was carried out by the Department of Mental Health, Faculty of Medical Sciences, NOVA University of Lisbon, with collaboration of the Portuguese Catholic University, and was funded by Champalimaud Foundation, Gulbenkian Foundation, Foundation for Science and Technology (FCT) and Ministry of Health. The Romania WMH study projects "Policies in Mental Health Area" and "National Study regarding Mental Health and Services Use" were carried out by National School of Public Health \& Health Services Management (former National Institute for Research \& Development in Health), with technical support of Metro Media Transilvania, the National Institute of Statistics-National Centre for Training in Statistics, SC, Cheyenne Services SRL, Statistics Netherlands and were funded by Ministry of Public Health (former Ministry of Health) with supplemental support of Eli Lilly Romania SRL. The South Africa Stress and Health Study (SASH) is supported by the US National Institute of Mental Health (R01-MH059575) and National Institute of Drug Abuse with supplemental funding from the South African Department of Health and the University of Michigan. The Psychiatric Enquiry to General Population in Southeast Spain - Murcia (PEGASUSMurcia) Project has been financed by the Regional Health Authorities of Murcia (Servicio Murciano de Salud and Consejería de Sanidad y Política Social) and Fundación para la Formación e Investigación Sanitarias (FFIS) of Murcia. The Ukraine Comorbid Mental Disorders during Periods of Social Disruption (CMDPSD) study is funded by the US National Institute of Mental Health (RO1-MH61905). The US National Comorbidity Survey Replication (NCS-R) is supported by the
National Institute of Mental Health (NIMH; U01-MH60220) with supplemental support from the National Institute of Drug Abuse (NIDA), the Substance Abuse and Mental Health Services Administration (SAMHSA), the Robert Wood Johnson Foundation (RWJF; Grant 044708), and the John W. Alden Trust. Louisa Degenhardt is supported by a NHMRC Senior Principal Research Fellowship (no. 1135991) and NIDA NIH grant R01 DA044170-02. John McGrath is supported by the Danish National Research Foundation (Niels Bohr Professorship), and the John Cade Fellowship (APP1056929) from National Health and Medical Research Council. A complete list of all within-country and cross-national WMH publications can be found at http://www.hcp. med.harvard.edu/wmh/.

\section{Declaration of Competing Interest}

The views and opinions expressed in this publication are those of the authors only and do not necessarily represent the views, official policy, or position of the US. Department of Health and Human Services or any of its affiliated institutions or agencies. Dr. Glantz's role on this study is through his involvement as a Science Officer on U01-MH60220. He had no involvement in the other cited grants. In the past 3 years, Dr. Kessler received support for his epidemiological studies from Sanofi Aventis; was a consultant for Johnson \& Johnson Wellness and Prevention, Sage Pharmaceuticals, Shire, Takeda; and served on an advisory board for the Johnson \& Johnson Services Inc. Lake Nona Life Project. Kessler is a co-owner of DataStat, Inc., a market research firm that carries out healthcare research. In the past 3 years, L.D. has received investigator-initiated untied educational grants for studies of opioid medications in Australia from Indivior, Mundipharma and Seqirus.

\section{Appendix A. Supplementary data}

Supplementary data to this article can be found online at https:// doi.org/10.1016/j.addbeh.2019.106128.

\section{References}

Adlaf, E. M., Begin, P., \& Sawka, E. (2005). Canadian Addiction Survey (CAS): A national survey of Canadians' use of alcohol and other drugs: Prevalence of use and related harms: Detailed report. Ottawa: Canadian Centre on Substance Abuse.

American Psychiatric Association (1980). Diagnostic and statistical manual (3rd ed.). Washington, D.C.: American Psychiatric Association.

American Psychiatric Association (2000). Diagnostic and statistical manual of mental disorders, fourth edition, text revision (DSM-IV-TR). Washington, DC: American Psychiatric Association.

Babor, T., Caetano, R., Casswell, S., et al. (2010). Alcohol no ordinary commodity : Research and public policy (2nd ed.). Oxford: Oxford University Press.

Barr, P. B., Salvatore, J. E., Maes, H., et al. (2016). Education and alcohol use: A study of gene-environment interaction in young adulthood. Social Science \& Medicine, 162, 158.

Baxter, A. J., Patton, G., Scott, K. M., et al. (2013). Global epidemiology of mental disorders: What are we missing? PLoS One, 8(6), e65514.

Bromet, E., Gluzman, S., Paniotto, V., et al. (2005). Epidemiology of psychiatric and alcohol disorders in Ukraine. Social Psychiatry and Psychiatric Epidemiology, 40(9), 681-690.

Caspi, A., Houts, R. M., Belsky, D. W., et al. (2014). The p factor: One general psychopathology factor in the structure of psychiatric disorders? Clinical Psychological Science, 2(2), 119-137.

Chen, C.-C., \& Yin, S.-J. (2008). Alcohol abuse and related factors in Asia. International Review of Psychiatry, 20(5), 425-433.

Cochrane, J., Chen, H., Conigrave, K. M., et al. (2003). Alcohol use in China. Alcohol and Alcoholism, 38(6), 537-542.

Conway, C. C., Forbes, M. K., Forbush, K. T., et al. (2019). A hierarchical taxonomy of psychopathology can transform mental health research. Perspectives on Psychological Science, 14(3), 419-436.

De Looze, M., Raaijmakers, Q., Ter Bogt, T., et al. (2015). Decreases in adolescent weekly alcohol use in Europe and North America: Evidence from 28 countries from 2002 to 2010. European Journal of Public Health, 25, 69-72.

ESPAD Group (2016). ESPAD report 2015: Results from the European school survey project on alcohol and other drugs. Luxembourg: Publications Office of the European Union.

GBD 2016 Alcohol Collaborators. (2018). Alcohol use and burden for 195 countries and territories, 1990-2016: A systematic analysis for the Global Burden of Disease Study 2016. The Lancet, 392(10152), 1015-1035. 
Glantz, M. D. (1992). A developmental psychopathology model of drug abuse vulnerability. In M. D. Glantz, \& R. W. Pickens (Eds.). Vulnerability to drug abuse. Washington, DC: American Psychological Association Press.

Glantz, M. D., \& Leshner, A. I. (2000). Drug abuse and developmental psychopathology. Development and Psychopathology, 12(4), 795-814.

Glantz, M. D., Medina-Mora, M. E., Petukhova, M., et al. (2014). Alcohol abuse in developed and developing countries in the World Mental Health Surveys: Socially defined consequences or psychiatric disorder? 23(2), 145-155.

Gordon, R., Heim, D., \& Macaskill, S. (2012). Rethinking drinking cultures: A review of drinking cultures and a reconstructed dimensional approach. Public Health, 126(1), $3-11$.

Grant, B. F., Goldstein, R. B., Saha, T. D., et al. (2015). Epidemiology of DSM-5 alcohol use disorder: Results from the national epidemiologic survey on alcohol and related conditions III. JAMA Psychiatry, 72(8), 757.

Grant, B. F., Stinson, F. S., Dawson, D. A., et al. (2004). Prevalence and co-occurrence of substance use disorders and independent mood and anxiety disorders : Results from the National Epidemiologic Survey on Alcohol and Related Conditions. Archives of General Psychiatry, 61(8), 807-816.

Grucza, R. A., Sher, K. J., Kerr, W. C., et al. (2018). Trends in adult alcohol use and binge drinking in the early 21st-century United States: A meta-analysis of 6 National Survey Series. Alcoholism: Clinical and Experimental Research, 42(10), 1939-1950.

Haro, J. M., Arbabzadeh-Bouchez, S., Brugha, T. S., et al. (2006). Concordance of the Composite International Diagnostic Interview Version 3.0 (CIDI 3.0) with standardized clinical assessments in the WHO World Mental Health surveys. International Journal of Methods in Psychiatric Research, 15(4), 167-180.

Hasin, D. S., Stinson, F. S., Ogburn, E., et al. (2007). Prevalence, correlates, disability, and comorbidity of DSM-IV alcohol abuse and dependence in the United States - results from the National Epidemiologic Survey on Alcohol and Related Conditions. Archives of General Psychiatry, 64, 830-842.

Heeringa, S., Wells, J., Hubbard, F., et al. (2008). Sample designs and sampling procedures. 14-32.

Helzer, J. E., \& Canino, G. J. (1992). Alcoholism in North America. Europe, and Asia. New York: Oxford University Press.

Jager, J., Keyes, K. M., \& Schulenberg, J. E. (2015). Historical variation in young adult binge drinking trajectories and its link to historical variation in social roles and minimum legal drinking age. Developmental Psychology, 51(7), 962-974.

Jan-Llopis, E., \& Matytsina, I. (2006). Mental health and alcohol, drugs and tobacco: A review of the comorbidity between mental disorders and the use of alcohol, tobacco and illicit drugs. Drug and Alcohol Review, 25(6), 515-536.

Kessler, R. C., Abelson, J., Demler, O., et al. (2004). Clinical calibration of DSM-IV diagnoses in the World Mental Health (WMH) version of the World Health Organization (WHO) Composite International Diagnostic Interview (WMHCIDI). International Journal of Methods in Psychiatric Research, 13(2), 122-139.

Kessler, R. C., Heeringa, S. G., Pennell, B. E., et al. (2018). Methods of the world mental health surveys. In K. M. Scott,, P. de Jonge,, \& D. J. Stein, (Eds.). Mental disorders around the world: Facts and figures from the WHO World Mental Health Surveys (pp. 940). Cambridge: Cambridge University Press.

Kessler, R. C., Ormel, J., Petukhova, M., et al. (2011). Development of lifetime comorbidity in the World Health Organization World Mental Health Surveys. Archives of General Psychiatry, 68(1), 90-100.

Kessler, R. C., \& Üstün, T. B. (2004). The World Mental Health (WMH) Survey Initiative version of the World Health Organization (WHO) Composite International Diagnostic Interview (CIDI). International Journal of Methods in Psychiatric Research, 13(2), 93-121.

Kotov, R., Krueger, R. F., Watson, D., et al. (2017). The hierarchical taxonomy of psychopathology (HiTOP): A dimensional alternative to traditional nosologies. Journal of Abnormal Psychology, 126(4), 454-477.

Kuntsche, E., Kuntsche, S., Knibbe, R., et al. (2011). Cultural and gender convergence in adolescent drunkenness: Evidence from 23 European and North American countries culture and gender in adolescent drunkenness. Archives of Pediatrics \& Adolescent Medicine, 165(2), 152-158.

Lai, H. M., Cleary, M., Sitharthan, T., et al. (2015). Prevalence of comorbid substance use, anxiety and mood disorders in epidemiological surveys, 1990-2014: A systematic review and meta-analysis. Drug and Alcohol Dependence, 154, 1-13.

Leifman, H. (2002). A comparative analysis of drinking patterns in six EU countries in the year 2000. Contemporary Drug Problems, 29(3), 501-548.

Leonard, K., \& Rothbard, J. (1999). Alcohol and the marriage effect. Journal of Studies on Alcohol, (s13), 139-146.

Livingston, M. (2014). Trends in non-drinking among Australian adolescents. Addiction, 109(6).

Lukassen, J., \& Beaudet, M. P. (2005). Alcohol dependence and depression among heavy drinkers in Canada. Social Science \& Medicine, 61(8), 1658-1667.

Mathers CD, Ayuso-Mateos JL. Global burden of alcohol use disorders in the Year 2000: summary of methods and data sources 2003. Available from: http://www.who.int/ healthinfo/statistics/bod_alcohol.pdf, accessed 2019.

Merikangas, K., Mehta, R., Molnar, B., et al. (1998). Comorbidity of substance use disorders with mood and anxiety disorders: Results of the international consortium in psychiatric epidemiology. Addictive Behaviors, 23(6), 893-907.

Miech, R. A., Johnston, L. D., O'malley, P. M., et al. (2017). Monitoring the future national survey results on drug use, 1975-2016: Volume I, secondary school students.

Moskalewicz, J., Room, R., \& Thom, B. (2016). Comparative monitoring of alcohol epidemiology across the EU. Baseline assessment and suggestions for future action synthesis report Warsaw, PARPA-the state agency for prevention of alcohol related problems.

Obot, I. S., \& Room, R. (2005). Alcohol, gender and drinking problems : Perspectives from low and middle income countries. Geneva: World Health Organization Department of Mental Health and Substance Abuse.

Peacock, A., Leung, J., Larney, S., et al. (2018). Global statistics on alcohol, tobacco and illicit drug use: 2017 status report. Addiction, 113(10), 1905-1926.

Rehm, J. (2016). How should prevalence of alcohol use disorders be assessed globally? International Journal of Methods in Psychiatric Research, 25(2), 79-85.

Rehm, J., Allamani, A., Aubin, H.-J., et al. (2015). People with alcohol use disorders in specialized care in eight different european countries. Alcohol and Alcoholism, 50(3), $310-318$.

Rehm, J., Mathers, C., Popova, S., et al. (2009). Global burden of disease and injury and economic cost attributable to alcohol use and alcohol-use disorders. Lancet (London, England), 373(9682), 2223.

Rehm, J., Rehn, N., Room, R., et al. (2003). The global distribution of average volume of alcohol consumption and patterns of drinking. European Addiction Research, 9(4), $147-156$.

Rehm, J., \& Room, R. (2017). The cultural aspect: How to measure and interpret epidemiological data on alcohol-use disorders across cultures. Nordic Studies on Alcohol and Drugs, 34(4), 330-341.

Rehm, J., Room, R., Van Den Brink, W., et al. (2005). Alcohol use disorders in EU countries and Norway: An overview of the epidemiology. European Neuropsychopharmacology, 15(4), 377-388.

Robins, L. N., Helzer, J. E., Croughan, J., et al. (1981). National Institute of Mental Health Diagnostic Interview Schedule: Its history, characteristics, and validity. Archives of General Psychiatry, 38(4), 381.

SAS Institute Inc 2019. (Cary, NC, USA).

Savic, M., Room, R., Mugavin, J., et al. (2016). Defining "drinking culture": A critical review of its meaning and connotation in social research on alcohol problems. Drugs: Education, Prevention and Policy, 23(4), 270-282.

Simpura, J., Karlsson, T., \& Leppänen, K. (2002). European trends in drinking patterns and their socioeconomic background. In T. Norström (Ed.). Alcohol in postwar Europe: Consumption, drinking patterns, consequences and policy responses in 15 European countries (pp. 83-114). Stockholm: National Institute of Public Health.

Steel, Z., Marnane, C., Iranpour, C., et al. (2014). The global prevalence of common mental disorders: A systematic review and meta-analysis 1980-2013. International Journal of Epidemiology, 43(2), 476-493.

Swendsen, J., Conway, K. P., Degenhardt, L., et al. (2010). Mental disorders as risk factors for substance use, abuse and dependence: Results from the 10-year follow-up of the National Comorbidity Survey. Addiction, 105(6), 1117-1128.

Taylor, B. (2007). Alcohol, gender, culture, and harms in the Americas: PAHO multicentric study final report. World Health Organization.

Toumbourou, J. W., Beyers, J. M., Catalano, R. F., et al. (2005). Youth alcohol and other drug use in the United States and Australia: A cross-national comparison of three state-wide samples. Drug and Alcohol Review, 24(6), 515-523.

Ulaş, H., Binbay, T., Kırlı, U., et al. (2017). The epidemiology of alcohol use in Izmir, Turkey: Drinking pattern, impairment and help-seeking. Social Psychiatry and Psychiatric Epidemiology, 52(7), 887-899.

Webb, C. P., Bromet, E. J., Gluzman, S., et al. (2005). Epidemiology of heavy alcohol use in Ukraine: Findings from the world mental health survey. Alcohol and Alcoholism, 40(4), 327-335.

White, A., Castle, I. P., Chen, C. M., et al. (2015). Converging patterns of alcohol use and related outcomes among females and males in the United States, 2002 to 2012. Alcoholism: Clinical and Experimental Research, 39(9), 1712-1726.

Wittchen, H.-U., \& Jacobi, F. (2005). Size and burden of mental disorders in Europe - a critical review and appraisal of 27 studies. European Neuropsychopharmacology: The Journal of the European College of Neuropsychopharmacology, 15(4), 357.

Wood, A. M., Kaptoge, S., Butterworth, A. S., et al. (2018). Risk thresholds for alcohol consumption: Combined analysis of individual-participant data for 599912 current drinkers in 83 prospective studies. The Lancet (LondonEngland), 391(10129), 1513-1523.

World Bank (2012). World development indicators 2012 (English). World development indicators. Washington, DC.

World Health Organization (2018). Global status report on alcohol and health 2018 Geneva, Switzerland: World Health Organization.

World Health Organization, Management of Substance Abuse Unit (2014). Global status report on alcohol and health. World Health Organization2014.

Yang, O., Zhao, X., \& Srivastava, P. (2016). Binge drinking and antisocial and unlawful behaviours in Australia. Economic Record, 92(297), 222-240.

Ystrom, E., Kendler, K. S., \& Reichborn-Kjennerud, T. (2014). Early age of alcohol initiation is not the cause of alcohol use disorders in adulthood, but is a major indicator of genetic risk. A population-based twin study. Addiction, 109(11), 1824-1832. 